\title{
The Vulnerability of Homes to Overheating in Myanmar Today and in the Future: A Heat Index Analysis of Measured and Simulated Data
}

\begin{abstract}
The integration of vernacular strategies in Myanmar housing seems to have remained remarkably resilient and is still the norm even in modern dwellings. However, no regard is given to the possible impact of climate change.

Using one-year monitored indoor and outdoor thermal environment data, typical and a morphed weather data representing future climate change scenarios, the authors investigated whether modern dwellings in Myanmar can provide thermal comfort in the present and future, and measured how vulnerable to overheating risks they are. Building envelope materials based on typical construction found locally and window shading were varied in the simulations, in order to understand their role in the resultant building performance.

The analysis showed that the number of hours above $30^{\circ} \mathrm{C}$ in 2019 doubled when compared to a typical weather year. This study contributes valuable insights into how the combined effect of air temperature and humidity will affect building thermal performance in future climate scenarios. Temperature readings reaching the 'danger' heat index threshold were $14.06 \%$ of the time in 2019 and only $5.49 \%$ in the typical weather year. This indicated that modern dwellings in Myanmar are facing two challenges: high vulnerability to extreme heatwave events, and inadequate response to increased mean air temperatures.
\end{abstract}

Keywords: Thermal comfort; Summer overheating; Heat-index temperature; Building thermal performance; Climate change in Myanmar. 


\section{Introduction}

Current climate change trends are expected to continue throughout the remainder of the $21^{\text {st }}$ century and beyond. The long-term effects of climate change include increased frequency and intensity of droughts, heat-related events (e.g. heatwave and bush fires), changes in precipitation patterns, stronger storms, intense solar radiation, and lengthened frost-free seasons. Furthermore, on the global scale, the number of cold days and nights has decreased, and the number of warm days and nights has increased, based on observations between 1951 and 2010 (IPCC, 2015). Different degrees of exposure to extreme climate significantly test the adaptability of buildings to perform in changing climate conditions (Roaf et al., 2005, p60). These adverse effects of climate change on buildings, both from sudden extreme weather events and from slowly changing climatic conditions, have profound impacts on the health, comfort, and quality of life of occupiers.

Myanmar, a country in Southeast Asia, was ranked second out of 183 countries in the longterm climate risk index for the period 1990-2009 (Harmeling et al., 2011), and for the period 1999-2018 (Eckstein et al., 2019). However, adapting buildings for climate change impact, particularly to extreme heatwave events, is still beyond the normal scope of what the built environment of Myanmar is prepared for.

Myanmar's 2014 Census data reported that only $16 \%$ of dwellings are made of brick and concrete, and $62 \%$ have corrugated metal roofs. On the other hand, $38 \%$ of dwellings are made of timber, $34 \%$ of dwellings are made of bamboo, and 33\% have thatched roofs (Ministry of Labour, 2015). The solutions for the latter are influences from vernacular architecture. The practices of vernacular housing seem to have remained remarkably resilient in Myanmar, although the types of materials used have changed (Bansal et al., 2015., Falconer et al., 2000). The vast majority of housing is naturally ventilated but a recent study revealed that the efficacy of this and other vernacular passive design techniques would not be sufficient to achieve 
thermal comfort in predicted future climate scenarios (Zune et al., 2020). Variations in weather caused by climate change, socio-political fluctuations that affect the availability of construction materials, and the rise of short-term solutions for thermal comfort by means of air-conditioning are increasingly prevalent in Myanmar. However, the impact of these on Myanmar housing had not been studied.

In this work, the authors attempt to close that gap by presenting: a) the analysis of an empirical data set collected in a typical home over a one-year period, including microclimate data collected in an urban setting; and b) the analysis of a typical home modelled in a dynamic simulation software and validated by the empirical data. The simulations utilised existing weather data, the monitored weather data, and a morphed weather data representing future climate change scenarios. Building envelope materials and window shading were also varied in the model based on typical construction found locally, in order to understand their role in the resultant building performance. The data sets were analysed in terms of the potential for heat stress using the heat index method. The research approaches and steps proposed and applied in this study is shown in Figure 1.

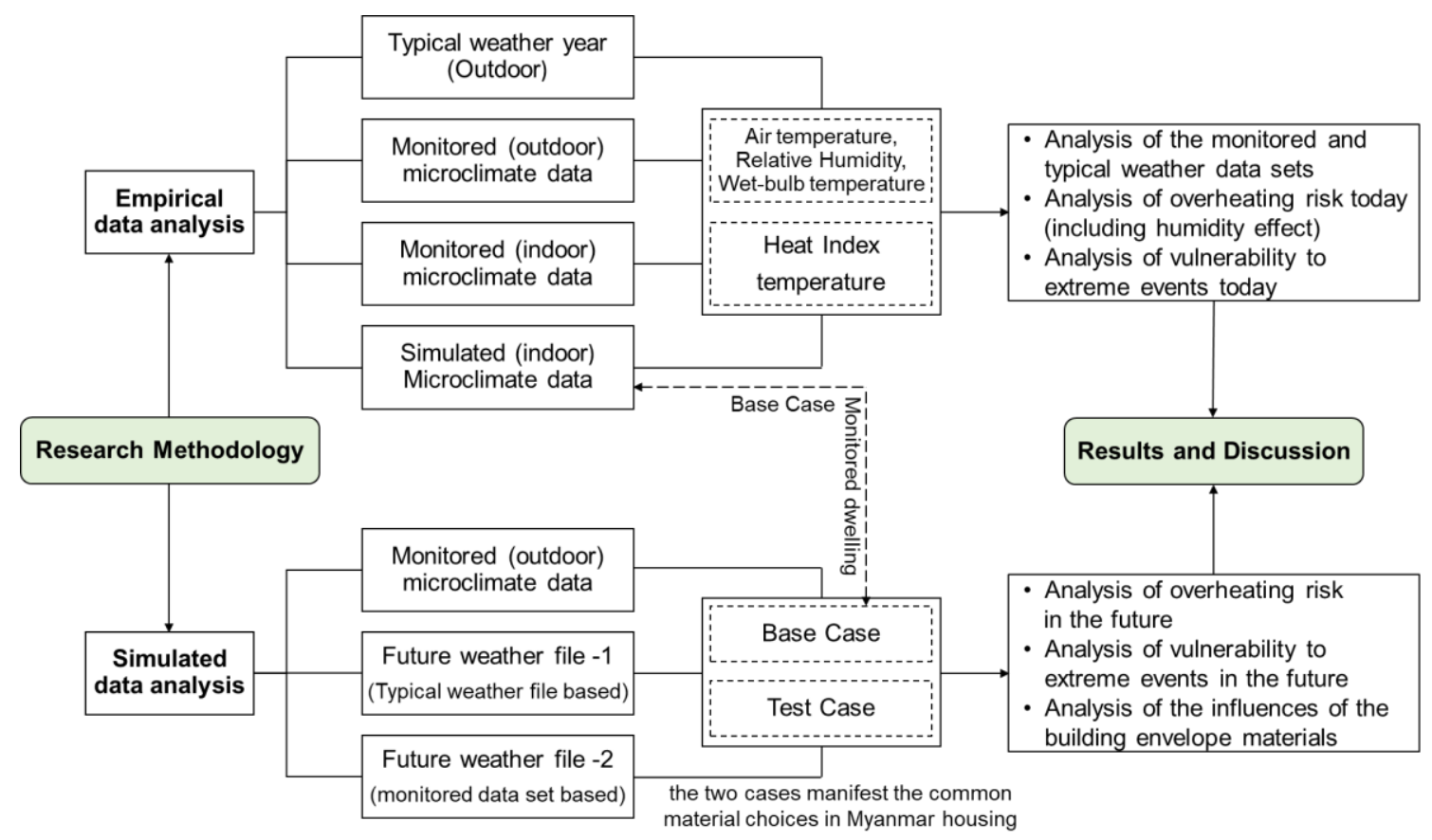

Figure 1. Research approaches and steps proposed and applied in this study 


\section{Context and background}

In this section, we discuss the effect of outdoor weather data on indoor thermal comfort standards, the reasoning behind the use of wet-bulb temperature in the analysis, and why the heat index method was chosen. We also include a review of relevant architecture strategies in the tropics, and an introduction to the context in Myanmar.

\subsection{Thermal comfort}

The American Society of Heating, Refrigeration and Air conditioning Engineers (ASHRAE) and the BS EN ISO 7730:2005 has defined thermal comfort as a psychological phenomenon (Nicol et al., 2005) that shows 'that state of mind which expresses satisfaction with the thermal environment' (ASHRAE, 2010., BSI, 2006). Humans worldwide have the same essential physiology and core temperature of around $37.5^{\circ} \mathrm{C}$, which is conceptualised as a thermodynamic machine in models to benchmark and maintain thermal comfort, regardless of great variety in human metabolism, activities, and cultural and climate differences ( al., 2005, p34). Skin temperature represents a critical temperature range or threshold (Roaf et al., 2005, p47). Below skin temperature $\left(32-35^{\circ} \mathrm{C}\right)$ a person can be cooled by convection; above it, they cannot because the ambient air is heating the body, not cooling it. Above this temperature, the body only is cooled by evaporation of sweat off the skin, which is why hot dry climates are more comfortable than hot wet ones because it is easy to lose moisture to the air when it is not saturated. For instance, heat stress can occur at a high temperature about $32^{\circ} \mathrm{C}$ with high relative humidity, as the body cannot maintain its core temperature of $37.5^{\circ} \mathrm{C}$, which limits the body's ability to keep cool through perspiration (CIBSE, 2014), while the same or higher temperatures in arid, low-humidity conditions are more tolerable as a consequence of increased ability to cool via perspiration. As a building acts as a third skin to protect from outdoor climates, the building needs to respond to heat, cold, ground and sky radiation, wind, water vapours, humidity and other stresses, and the various parts of the building may be 
considered environmental control devices (Rapoport, 1969). The thermal performance of buildings is thus influenced not only by outdoor climates but also by the building envelope design and occupants' physiological, psychological, social, and behavioural items. Besides occupants' subjective perceptions, thermal comfort depends on a number of conditions. The review of this section, therefore, covers these areas - thermal comfort in heatwave situation and the impacts of different environmental parameters on thermal comfort.

Climate change has been described as 'the biggest global health threat of the $21^{\text {st }}$ Century' (Costello et al., 2009). Short-term peaks in mortality are associated with heatwaves ( $\underline{\text { Nicol et }}$ al., 2005). During the 2003 European heatwave, many European countries reached recordbreaking temperatures, including $41.1^{\circ} \mathrm{C}$ in Auxerre (France), $45.2^{\circ} \mathrm{C}$ in Seville (Spain), $46^{\circ} \mathrm{C}$ in Sicily (Italy), $38.5^{\circ} \mathrm{C}$ in Kent (United Kingdom), and $48^{\circ} \mathrm{C}$ in Amareleja (Portugal) (WMO, 2010), and resultant deaths across the continent exceeded 70,000 (Robine et al., 2008). Likewise, during the 2010 heatwave in Myanmar, the outdoor maximum dry-bulb temperature reached $47.2^{\circ} \mathrm{C}$ in Myinmu, $46.5^{\circ} \mathrm{C}$ in Myingan, $45.7^{\circ} \mathrm{C}$ in Monywa, $45.5^{\circ} \mathrm{C}$ in Magway, $45^{\circ} \mathrm{C}$ in Mandalay, $44^{\circ} \mathrm{C}$ in Meiktila, and $42.5^{\circ} \mathrm{C}$ in Yangon (Phyu, 2010). As a result, more than 230 people died of heat-related illness as a consequence of 2010 heatwave, a record from the health authorities of Mandalay (Nai, 2010). The climate contexts of Europe and Myanmar are different, and their thermal neutrality might vary according to the cultural mechanisms. Therefore, the science of thermal comfort has developed based on a number of subjective perceptions and objective environmental parameters, listed below.

Dry-bulb temperature: The dry-bulb temperature (DBT) is a measure of ambient air temperature, which does not vary with the moisture content of the air. The ambient air temperature is used to express as a threshold to define thermal comfort due to its indication of heat content without the effect of the moisture of the air. 
Relative humidity: The relative humidity $(\mathrm{RH})$ is the ratio of vapour pressure to saturation vapour pressure at the same dry bulb temperature, expressed as a percentage (\%). Humidity has little effect on feelings of warmth unless the skin is damp with sweat. The physiological results from an environmental chamber for the influence of relative humidity on thermal comfort showed that sufficient evaporation heat losses from the body surfaces are not maintained at higher humidity (Jing et al., 2013). If the influence of humidity on warmth in moderate thermal environments is ignored, humidity in the range $40-70 \% \mathrm{RH}$ is generally acceptable (CIBSE, 2015), but thermal discomfort can be happened by high humidity in warm environments.

Wet-bulb temperature: The wet-bulb temperature (WBT) is equal to the DBT at $100 \% \mathrm{RH}$, however, the value of WBT is lower than the DBT due to its cooling effect of evaporation. The WBT is widely used in the heat-stress index to assess health risks in physical work situations based on the heat-humidity threshold. Beyond the threshold value of WBT $35^{\circ} \mathrm{C}$, any exposure for more than six hours would probably be intolerable even for the fittest of humans, resulting in hyperthermia (Pal and Eltahir, 2016). The study by Sherwood and Huber (2010) reported that human adaptability has a limitation on climate change which is a consequence of heat stress caused by the WBT. The WBT equation ${ }^{1}$ generated by Stull (2011), as shown below, is presented for wet-bulb temperature as a function of ambient dry-bulb temperature and relative humidity at standard sea level pressure.

$$
\begin{aligned}
\mathrm{WBT}= & \mathrm{T} \operatorname{atan}\left[0.151977(\mathrm{RH}+8.313659)^{\wedge 1 / 2}\right]+\operatorname{atan}(\mathrm{T}+\mathrm{RH}) \\
& -\operatorname{atan}(\mathrm{RH}-1.676331)+0.00391838(\mathrm{RH})^{\wedge 3 / 2 *} \operatorname{atan}(0.023101 \mathrm{RH}) \\
& -4.686035
\end{aligned}
$$

\footnotetext{
${ }^{1}$ The WBT equation was from an empirical inverse solution which was valid for relative humidity between $5 \%$ and $99 \%$ and air temperatures between $-20^{\circ} \mathrm{C}$ and $50^{\circ} \mathrm{C}$, except for situations having both low humidity and cold temperature. Over the valid range, errors in wet-bulb temperature range from $-1^{\circ}$ to $+0.651^{\circ}$, with mean absolute error of less than $0.3^{\circ} \mathrm{C}$ (Stull, 2011).
} 
Where, $\quad \mathrm{T}=$ ambient dry bulb temperature $\left({ }^{\circ} \mathrm{C}\right)$

$$
\mathrm{RH}=\text { relative humidity (integer percentage). }
$$

By using Equation 1, the WBT can be calculated to express temperatures for damp conditions. As the WBT provides a physically based relationship to the human body's core temperature based on the heat-humidity threshold, the impact of climate change on the WBT are important to check; for instance, in the current climate, the WBT rarely exceeds $31^{\circ} \mathrm{C}(\underline{\mathrm{Pal}}$ and Eltahir, 2016).

Heat-index temperature: The degree of heat stress can be calculated by using the heat index equation. Heat Index ${ }^{2}$ is a measure of how hot it really feels when relative humidity is factored in with the actual air temperature (National Weather Service, 2019., Rothfusz, 1990), therefore the values depend on the comprehensive contextual climate factors. An ersatz version of the heat index equation is expressed in Equations 2 and 3.

$$
\begin{aligned}
\mathrm{HI}\left({ }^{\circ} \mathrm{C}\right)= & -8.78469475556+1.61139411 \mathrm{~T}+2.33854883889 \mathrm{R} \\
& -0.14611605 \mathrm{~T} \mathrm{R}-0.012308094 \mathrm{~T}^{2}-0.0164248277778 \mathrm{R}^{2} \\
& +0.002211732 \mathrm{~T}^{2} \mathrm{R}+0.00072546 \mathrm{~T} \mathrm{R}^{2}-0.000003582 \mathrm{~T}^{2} \mathrm{R}^{2}
\end{aligned}
$$

In Equation (2), $\mathrm{T}=$ ambient dry bulb temperature $\left({ }^{\circ} \mathrm{C}\right)$,

$$
\mathrm{R}=\text { relative humidity (integer percentage). }
$$

Adjustment of $\mathrm{HI}\left({ }^{\circ} \mathrm{F}\right)=[(\mathrm{R}-85) / 10] *[(87-\mathrm{T}) / 5]$

In Equation (3), $\mathrm{T}=$ ambient dry bulb temperature $\left({ }^{\circ} \mathrm{F}\right)$,

therefore, a unit conversion needs from ${ }^{\circ} \mathrm{C}$ to ${ }^{\circ} \mathrm{F}$.

\footnotetext{
${ }^{2}$ The heat index was initially developed in 1978 by George Winterling as the 'humiture' and was adopted by the US's National Weather Service a year later. It is driven from work carried out by Robert G. Steadman. The computation of the heat index is a refinement of a result obtained by multiple regression analysis carried out by Lans P. Rothfusz and described in a 1990 National Weather Service (NWS) Technical Attachment (SR 90-23). The equations use Heat Balance equations, which contains a list of 20 assumption factors as a fixed condition to compute how the factors affect a given situation.
} 


$$
\mathrm{R}=\text { relative humidity (integer percentage). }
$$

The heat-index equations were originally generated by using the Fahrenheit scale (Rothfusz, 1990), therefore, the Equation (2) shown here is a conversion for the Celsius scale. It is important to note that Equation (2) is obtained by multiple regression analysis and has an error of $\pm 0.72^{\circ} \mathrm{C}\left( \pm 1.3^{\circ} \mathrm{F}\right)$. If the $\mathrm{RH}$ is greater than $85 \%$ and the temperature is between $26.67^{\circ} \mathrm{C}\left(80^{\circ} \mathrm{F}\right)$ and $30.56^{\circ} \mathrm{C}\left(87^{\circ} \mathrm{F}\right)$, an adjustment is necessary using Equation (3), which was generated using the Fahrenheit scale. Since the body evaporation through the wind passing over perspiring skin (windchill factor) was excluded in the equations, the heat index equations only provide a limited estimate of thermal comfort. Moreover, the Rothfusz regression is not valid for extreme temperature and relative humidity conditions beyond the range of data considered by Steadman (Steadman, 1979), and the regression is not appropriate when the conditions of temperature and humidity warrant a heat index value below about $26.67^{\circ} \mathrm{C}\left(80^{\circ} \mathrm{F}\right)$.

The heat index temperature (HT) is generated from a heat balance condition with a list of 20 fixed assumption factors ( temperature and atmospheric moisture (humidity). The effects of heat index temperatures on occupants can be grouped by temperature and relative humidity, and their effects on health concern can be defined as four-stages: 'caution, extreme caution, danger, and extreme danger'. Figure 2 shows the four stages and how a heat index temperature varies according to the related ambient DBT and RH. The heat index values can be varied between shady condition and exposure to full sunshine, and also between light wind conditions to strong winds; therefore, Figure 2 has further limitation due to its reference in the Equations.

Despite the limitation of the fixed assumptions, the heat-index equation has advantages to check the simultaneous effect of air temperature and humidity, both of which generate either comfort or heat stress. For instance, at the AT $30^{\circ} \mathrm{C}$, if the RH is $80 \%$, the $\mathrm{HT}$ is $38^{\circ} \mathrm{C}$, which is an 'extreme caution' stage. Nevertheless, as airflow rates affect the adaptive thermal comfort 
of a free-running building, one should not forget that the airflow rate in the heat index equations is a fixed assumption.

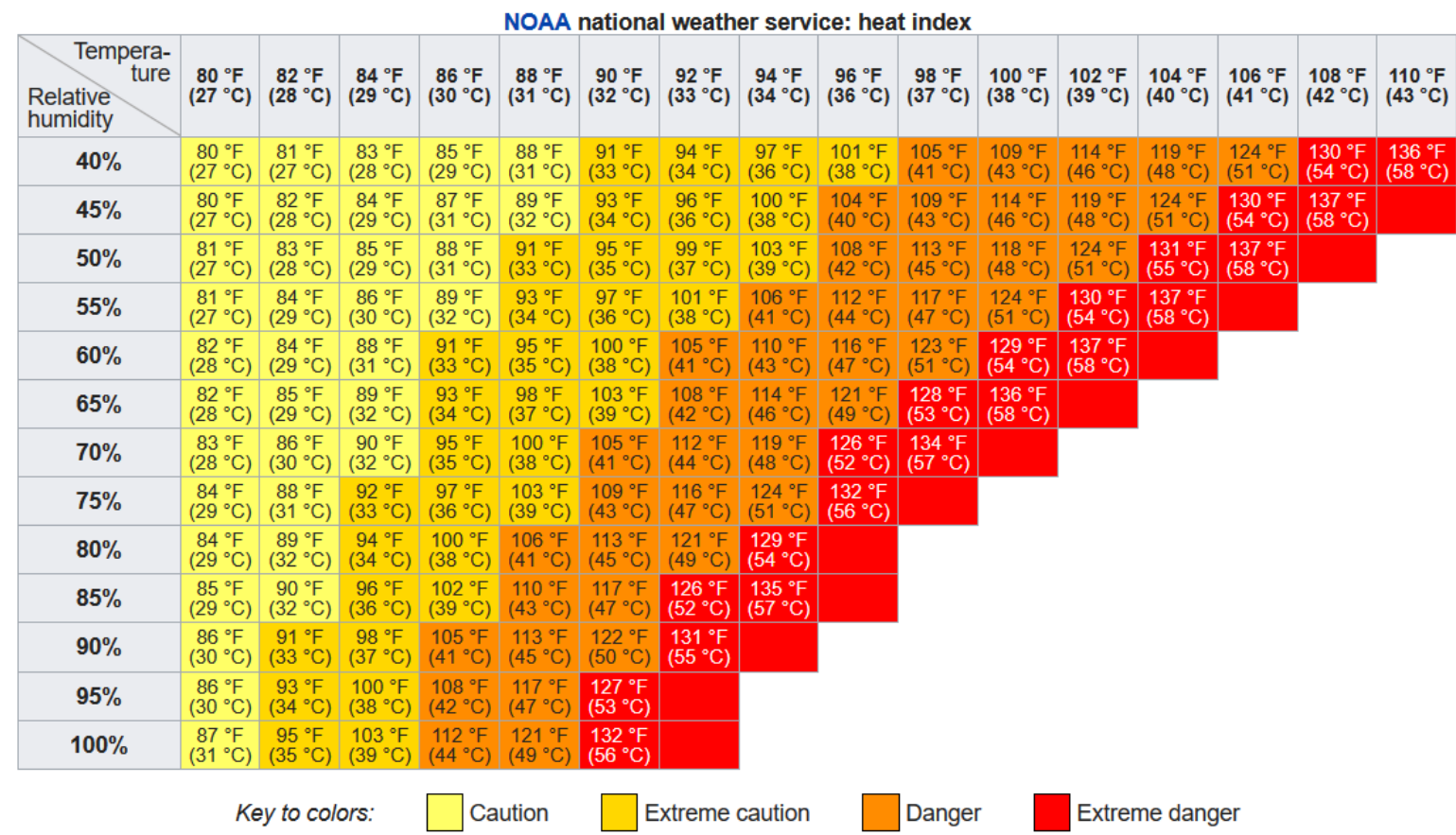

Figure 2. NOAA heat index temperature through temperature-humidity scale (National Weather Service, 2019)

In free-running mode, a building microclimate changes in relation to its outdoor weather, without consuming energy for the purpose either of heating or cooling (CIBSE, 2015); the building is thus naturally ventilated for thermal comfort (ASHRAE, 2013). Values for overheating thresholds for free-running buildings vary in different standards. Many scientific studies have proposed the optimum comfort temperature with regression equations for a naturally ventilated building as an adaptive model, in which either means outdoor dry bulb temperature (deDear and Brager, 2002) or running mean outdoor air temperature (Nicol and Humphreys, 2010) or prevailing mean outdoor air temperature (ASHRAE, 2013) are considered. ASHRAE has suggested that the prevailing mean outdoor temperature should be greater than $10^{\circ} \mathrm{C}$ and less than $33.5^{\circ} \mathrm{C}$ (ASHRAE, 2013). The Chartered Institution of Building Services Engineers (CIBSE) has suggested that the internal operative temperature (a combination of mean radiant temperatures and air temperatures) of a free-running building 
should not exceed $30^{\circ} \mathrm{C}$ (CIBSE, 2015). Field experiments in naturally ventilated buildings in Singapore (deDear et al., 1991) and the study of the thermal response for the Thai office environment (Busch, 1990) present a good agreement of the thermal neutrality $28.5^{\circ} \mathrm{C}$ for the internal operative temperature. All these thresholds are based on their specific databases that contain different building classification, the derivation of the neutral temperature, and the outdoor temperature (Nicol and Humphreys, 2010). As Singapore and Thailand are geographically close to Myanmar, the question arises of whether the Myanmar climate and buildings have a similar value of thermal neutrality in free-running mode.

Despite the universal representation of skin temperatures for a critical threshold, humans worldwide have slightly different thermal neutrality because of differences in their organisms and cultural mechanisms. Thus, our temperature regime is not a simple consequence of thermal needs but rather a product of social and economic conditions (Levins and Lewontin, 1985., Nicol et al., 2005, p110). Nevertheless, symptoms of thermal discomfort and health risks can occur outside the thermal comfort range, including sudden heart death, heart failure, heatstroke, and other health risks related to hypertension and hypotension (WHO, 1009), the results of 2003 heatwave in Europe and 2010 heatwave in Myanmar are examples. The thermal thresholds for building design are crucial for the survival of thermal technology (Roaf et al., 2005, p46); however, to date, no research and assessments provide the thermal threshold of the free-running buildings for the Myanmar context. Due to the lack of existing researches, in addition to CIBSE and ASHRAE's threshold for naturally ventilated buildings, the heat index equations and wet-bulb temperature equations are proposed in this study to analyse the weather and indoor thermal environment data so humidity can be appropriately accounted for. 


\subsection{Myanmar context}

Myanmar is located in the tropical and subtropical climate zones of Asia and experiences three distinct seasons - the hot, wet, and cold seasons - that is annually changed by monsoon onset time and withdrawal time due to its location around the Tropic of Cancer. According to the report "Assessing the Climate Risks in Myanmar", national annual average temperatures are projected to rise by 0.7 to $1.1^{\circ} \mathrm{C}$ compared to the $1980-2005$ base period, while warming trends may accelerate beyond 2040, raising average temperatures by 1.3 to $2.7^{\circ} \mathrm{C}$ ( $\underline{\text { Horton et }}$ al., 2017). On the other hand, rainfall is projected to increase by $40 \%$ in the wet season compared with the 1980-2005 base period, although the rainfall is projected a decrease in the hot and cold seasons (Horton et al., 2017). According to records covering the period 19552015, late monsoon onset time and early monsoon withdrawal time (Aung et al., 2017) indicate a slow-changing climate condition over those sixty years. E1 Nino years are linked to a shortterm period of warm ocean surface temperature in the tropical Pacific, and likely cause long durations of high maximum temperatures; higher temperatures and heatwave events were recorded in Myanmar for those years (Aung et al., 2017).

As shown in Figure 3, Myanmar has been experiencing long-term climate risk, climate shift, changes of monsoon season, accelerated warming trends, and increased risk of extreme events. According to associated predictions, Myanmar might experience warmer and drier winters, hotter and more extreme summers, and more rainfall during a shorter monsoon time (incidentally, this also implies more torrential rain and flooding). These effects will continue to be felt for decades, and all these changes are inevitable. In terms of the scope for thermal environments in buildings, in the near future, Myanmar housing might face increasing challenges due to the high probability of more frequent heatwaves and a significant increase in daily average temperatures, which were not fully or systematically considered in current housing design practices for thermal comfort. 

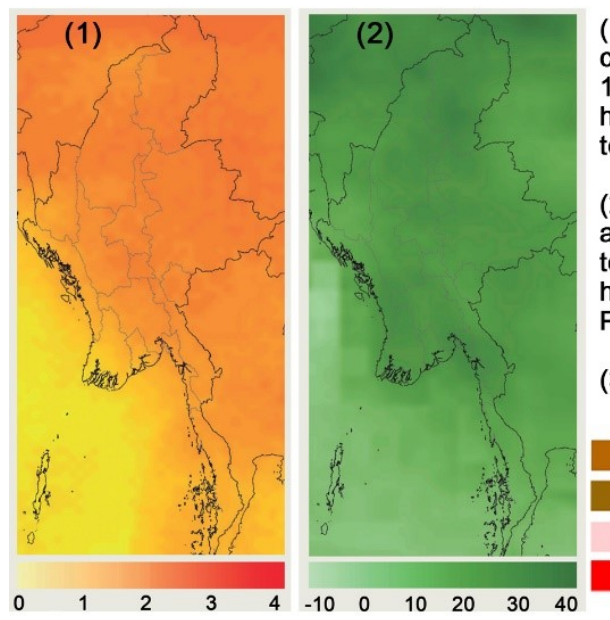

(1) Average annual temperature change in mid-century relative to 1980-2005 base period, high estimate mide-century, temperature $\left({ }^{\circ} \mathrm{C}\right)$.

(2) Average annual rainfall percentage change in mid-century relative to $1980-2005$ base period,

high estimate mide-century,

Precipitation Change (\%)

(3) Koppen Climate Shift in Myanmar

Mixed humid subtropical climate, Cwa Subtropical higthland climate, $\mathrm{Cwb}$ Equatorial winter dry climate, Aw

Tropical monsoon climate, Am
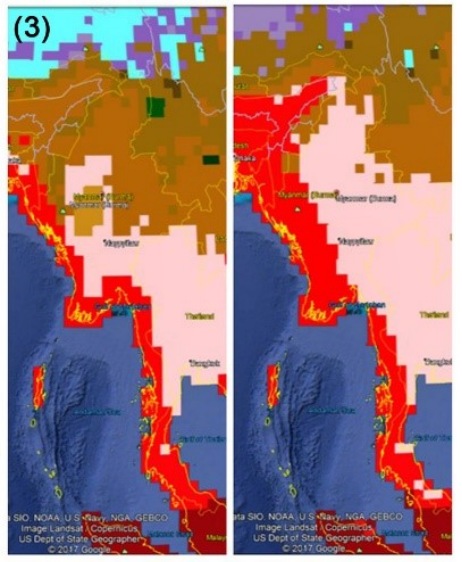

1976-2000 2076-2100 (A1F1)

Figure 3. (1) Predicted temperature change in Myanmar; (2) Predicted precipitation change in Myanmar (Horton et al., 2017., NASA, 2015); (3) Koppen climate shift in Myanmar (Zune, 2017)

In this work, Mandalay was selected for this building microclimate data monitoring work and simulation experiments. Mandalay, located centrally in the country, was founded in 1857 as the last royal capital of Myanmar, and it is the country's second-largest city. Bordering the Arakan Mountains, Mandalay is well known for its number of moderate to severe hot days, although the city does not experience hot semi-arid climate. Mandalay features a noticeably warm summer and an equal length of wet and dry seasons. According to the Koppen-Geiger climate classification, Mandalay exhibits the equatorial winter dry climate (Kottek et al., 2006). In the typical weather year, the annual average temperature of Mandalay is $26.9^{\circ} \mathrm{C}$, and the average daily highest temperature in the hottest month is $38.16^{\circ} \mathrm{C}$. During 1981 to 2010 , Mandalay ranked the third place for the maximum temperature range greater than $40^{\circ} \mathrm{C}$, with the record of 324 days in April, 171 days in May, and 46 days in March (Aung et al., 2017). During the 2010 heatwave in Myanmar, Mandalay reached $45^{\circ} \mathrm{C}$, which was the highest summer extreme temperature in 64 years ( $\underline{\text { Phyu, 2010) }}$.

Long-term historical weather data and future weather data are generally unavailable or limited in Myanmar. The typical weather file used in this paper was generated by Huang et al. (2014) for ASHRAE and is accepted as standard data for simulation; it does not take into account urban heat island (UHI) effect. The typical weather data set was created with data 
collected from 2005 to 2013, less than a decade. Using a weather file (either historical or typical) or weather data set, the psychrometric chart plots a series of climatic elements which includes dry-bulb temperature, wet-bulb temperature, relative humidity, the specific volume of air, dew point, humidity ratio and enthalpy. A psychrometric chart can be used to express thermal comfort, design strategies, and energy requirements for strategies tailored to specific climates. Figure 4 shows the findings from using a psychrometric chart to analyse a typical weather year of Mandalay.
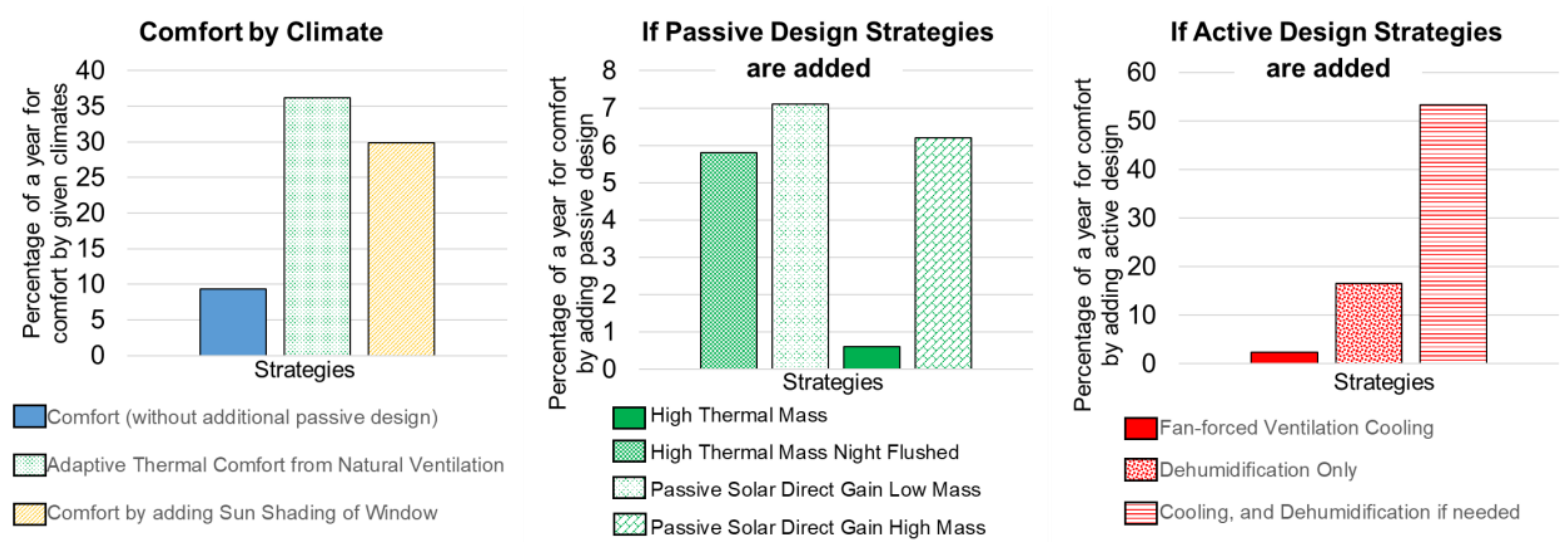

Figure 4. Comparison of the results of the psychrometric chart for Mandalay [The chart was generated using the typical weather year data from Huang et al. (2014)]

The psychrometric chart for Mandalay indicates that comfort is achieved for less than $10 \%$ of the time in a year if no passive design strategies are adopted. If passive design strategies were considered, a time within thermal comfort could increase up to $35 \%$ by adding natural ventilation for adaptive thermal comfort, and up to $30 \%$ by adding sun shading to windows. Although the percentage of a year for thermal comfort could increase by adding the use of high thermal mass coupled with night flushed ventilation and passive solar direct gain, the effectiveness of thermal mass on the indoor thermal comfort had less benefit compared to the use of shading and natural ventilation for passive cooling in Mandalay. When the active design strategies were considered, the use of fan-forced ventilation alone was not as significant as the use of dehumidification. By combining active cooling with dehumidification, indoor thermal comfort could be maintained for more than $50 \%$ of the year in Mandalay. In addition to the 
characteristics of the tropical climate contexts and predictions for a changing climate condition in Myanmar, Figure 4 provides fundamental knowledge to understand the unique attributes of a climate and how their impacts on the thermal comfort.

\subsection{Tropical architecture}

The tropics are defined as being from the equator to $25^{\circ}$ north and south latitudes. This band of the planet is characterised by heavy rainfall, high humidity, and intense solar radiation, but cloudiness causes diffuse solar radiation and lower potential for radiative sky cooling. In the tropics, the minimum average temperature is usually above $18^{\circ} \mathrm{C}$, with little daily and seasonal variations ( $\underline{\text { Rosenlund, 2000) }}$. In response to these climatic characteristics, passive cooling used in tropical vernacular architecture is predominantly dependent on a number of passive design techniques including choice of lightweight building materials, natural ventilation, built form and shading for thermal comfort, to cope with humid heat in the tropics (Oakley, 1961). In addition to the form, the use of roof insulation and a ceiling with moderate insulation prevents intense solar heat gain. The use of lightweight timber or bamboo walls and raised, high floors allows increased airflow around and under buildings. Tropical buildings tend to have several openings to provide cross-ventilation. High vents prevent the creation of hot air pockets under the ceiling, to remove hot air inside and avoid mould (Rosenlund, 2000., Zune et al., 2020). All these tropical vernacular architecture mechanisms can be seen in vernacular Myanmar (Zune et al., 2020), Thai (Stagno, 2001., Tantasavasdi et al., 2001), Malaysian (Toe and Kubotab, 2015), Indonesian (Loupis, 1983., Stagno, 2001), and Vietnamese dwellings (Nguyen et al., 2011) throughout Southeast Asia and Costa Rica (Stagno, 2001); they share strong similarities and a great variety of passive design.

Climatic considerations in vernacular architecture, and climate change, in particular, can often be of secondary importance, after behavioural, economic and cultural influences, in the evolution of detailed design (Meir and Roaf, 2006, p219). Therefore, there is always a need to 
revisit and investigate the thermal performance of vernacular architecture for present and future climate contexts. Many studies have contributed a great deal to our knowledge of vernacular design techniques in the tropics and their thermal performance in the present and recent climate conditions. Natural ventilation design for Thai houses found that the climatic condition of Bangkok only provides thermally comfortable indoor environments for $20 \%$ of the year, even in suburban areas, and the comfort duration can only be improved by integrating additional passive design techniques; the study was conducted based on 10-year weather database in 2000 (Tantasavasdi et al., 2001). Passive design techniques used in the vernacular housing in Vietnam enabled thermally acceptable conditions for $58.21 \%$ of the year, and $6 \%$ of the total time in which indoor air temperature exceeded $31^{\circ} \mathrm{C}$ (Nguyen et al., 2011). Likewise, the study of the Malay houses found that the periods of indoor operative temperatures exceeded $47 \%$ above the ASHRAE's $80 \%$ comfortable upper limit, based on adaptive thermal comfort equation s(Toe and Kubotab, 2015). A simulation experiment for Myanmar housing found that for approximately $20 \%$ of the year indoor air temperatures are above $32^{\circ} \mathrm{C}$ in timber housing located in the tropical monsoon climate zone and the equatorial winter dry climate zone (Zune et al., 2020). What can be learned from the existing literature is that although "the built form and materiality of vernacular buildings may suggest their climatic provenance, in itself, this is hardly proof of all-year environmental performance" (Weber and Yannas, 2014), and the same inference is true for thermal performance.

As the resultant environment is variable in a naturally ventilated building in the tropics, time becomes an important parameter in defining thermal performance criteria (Forwood, $\underline{1995, \mathrm{p} 178}$ ). For warm, humid climates with little diurnal temperature variation, heat storage has no advantage, and heavy construction can hinder maximum ventilation (Rapoport, 1969, p93); therefore, the use of lightweight building materials for walls and floors are often found in tropical vernacular architecture. As the daytime temperatures have increased in the tropics, 
and will further increase in future climate scenarios, both frequency distributions of temperatures and the length of high-intensity temperature are the foremost climatic parameters in selecting either thermal mass or lightweight building materials. If the longer length of high daytime temperatures of the outdoor climate is similar to the internal environment due to the results of lightweight in construction, there might have 'counter-intuitive' in the sense that those naturally ventilated buildings will not able to perform as assumed.

Regarding the building envelope materials, there is a classic dilemma for warm-humid climate building design in whether to choose heavy or lightweight building envelopes, coupled

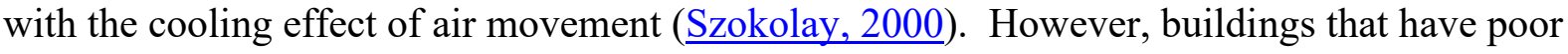
insulation characteristics, or are lightweight, with low thermal capacity, will be as likely to produce uncomfortable indoor temperatures during hot summers as well as cold winters (Nicol et al., 2005, p136). As a consequence of climate change, more frequent heat is predicted for the tropics, with longer and more extreme summers; therefore, the thermal performance of building envelope material properties must be appropriately prepared to deal for extremes of weather as well as typical characteristics of tropical climates.

It should be noted in this regard that 'modern' dwellings in the context of Myanmar do not comprise conventional western-style housing units, but simple constructions with metal sheet roofs and brick walls (Zune et al., 2020). Regarding the brick walls, there are three different typical brick wall thicknesses -4.5 inches, 9 inches, or 13.5 inches; this is because $3 \times 4.5 \times 9$ inches is a common brick size in Myanmar. According to the layers of the brick, the building envelope thermal performance varies; however, there is a knowledge gap in the reasoning behind the selection of the building envelope properties, such as heavy or lightweight. When the intensity of temperature has increased, warming trends have accelerated and the rainfall pattern has changed in the future climate change scenarios, the choice of heavy or lightweight building envelopes with its appropriate ventilation mode is a challenging task for the Myanmar 
housing industry. A fundamental aim of this work is therefore to understand how building thermal performance can be improved to meet required comfort expectations in changing climate conditions, considering context-appropriate solution.

\section{Methodology}

In this study, we have investigated how a modern dwelling responded to the present climate of Mandalay using monitored indoor and outdoor thermal environment data sets. A comparison between the monitored data and the results of the simulation was undertaken in order to increase the confidence in the model, which was then used for thermal performance prediction of two different building envelopes. The impacts of changing climate conditions for two cases were discussed based on their results for a typical weather year, the monitored weather year 2019, and two future weather files generated for this work.

\subsection{Monitoring processes}

The monitored dwelling, shown in Figure 5, is a typical house located in a dense urban environment in Mandalay. The dwelling faces almost due north, and is adjacent to similar detached masonry houses. The whole building covers an area of about $43.05 \mathrm{~m}^{2}$, with a maximum length of $6.92 \mathrm{~m}$ and a maximum width of $6.22 \mathrm{~m}$, and the total floor area is about $86.1 \mathrm{~m}^{2}$. The multi-purpose ground floor layout consists of a living room at the front and open concept kitchen and dining room at the back. There are two bedrooms on the upper floor.

One big door at the front side of the ground floor serves as an entrance and allows for ventilation and daylight. Each bedroom has one window each, and glass blocks which are aligned to the face of the front entrance door. High-level windows at the backside of the wall, shown in Figure 7, allow cross-ventilation. The ventilation from all sides of the walls and the use of high vents can be seen in the selected dwelling. The dwelling has thicker walls (13.5 inches), and close assumptions for material properties of the dwelling were obtained from the 
owner. The dwelling was not selected at random, rather it was conveniently selected due to the owner's familiarity with the subject (as an engineer), its location in a residential area, its fully residential function (as opposed to shophouses), and the availability of facilities for electricity and internet access throughout the year (in Myanmar, electricity and internet access is still limited, and services can be intermittently interrupted, even in the capital).
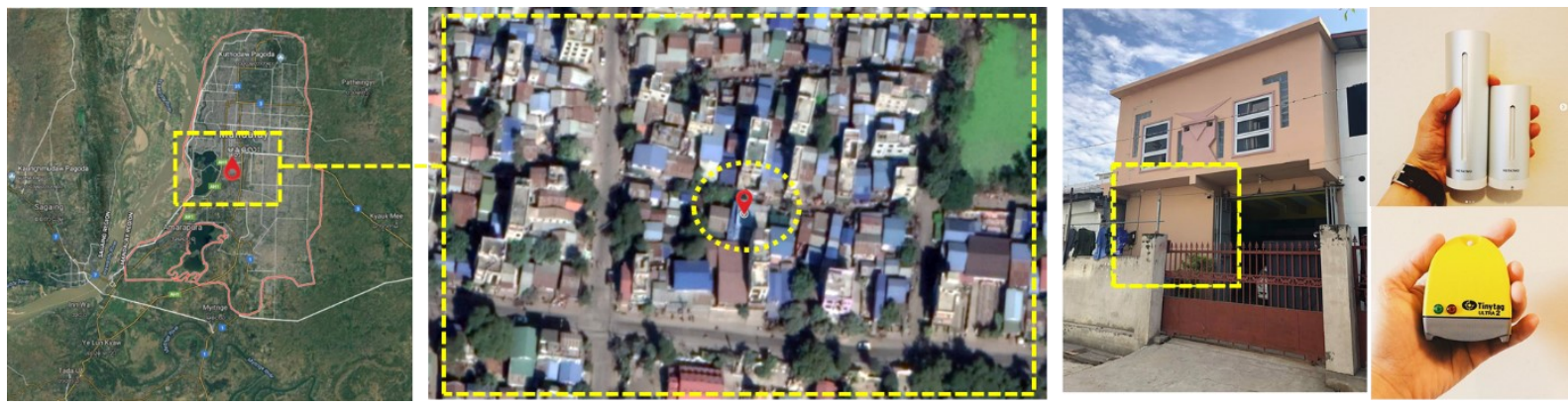

Figure 5. Location of the monitored dwelling in Mandalay and instruments for measurement

The monitoring work was conducted in the living room located on the ground floor (Figure 6), which was in free-running mode. The dwelling rarely had high activities while the measurements were undertaken; only three occupants used the house (early morning and evening in the living room, and night-time in the bedrooms). The windows and doors were frequently open from the morning to late evening (mainly for ventilation). As the space of the ground floor is an open layout, some internal gains occurred when the kitchen was used. All these activities and internal gains were considered in the simulations.

The indoor and outdoor thermal environment data were continuously monitored from the $1^{\text {st }}$ of January 2019 to the $31^{\text {st }}$ of December 2019, at 30-minute intervals, using Netatmo weather station and anemometer. The Netatmo is a prime example of the convenience of stateof-the-art technology that enables the user to remotely track real-time weather data in monitored environments (Netatmo, 2019). The weather station consists of two elegant aluminium units, one indoor and one outdoor sensor. The indoor module measures the indoor temperature, humidity, carbon dioxide level, noise, and air pressure through its sensors. The 
outdoor module measures the real-time weather data, such as temperature and relative humidity from the shaded place.

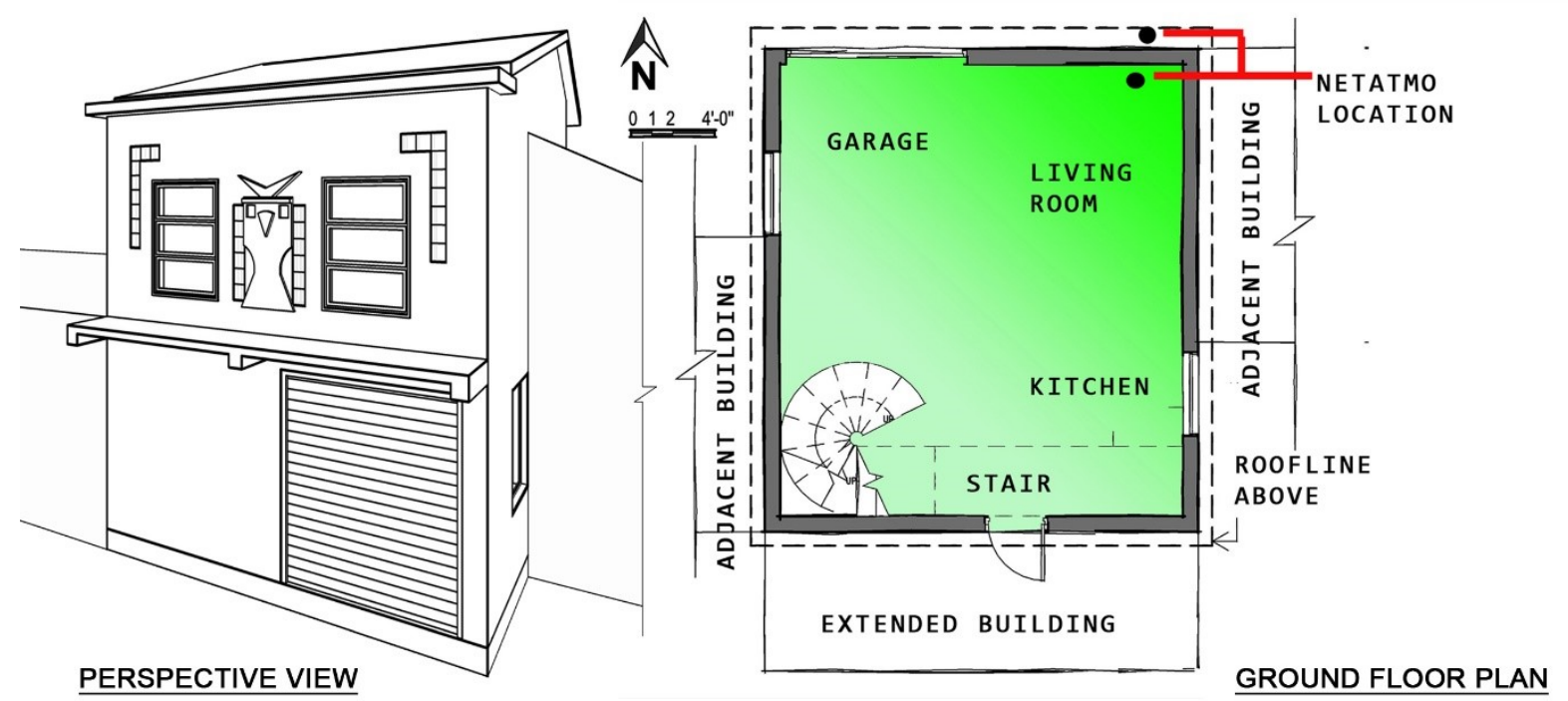

Figure 6. Monitored dwelling in Mandalay and location of a monitored room

Although Chapman et al. (2017) have reported promising results of Netatmo with validation; the accuracy of the monitored data is $\pm 3 \%$, which is challenging for scientific study. Alternatively, several projects reported that the Tinytag data loggers accurately monitor temperatures ranging from $-25^{\circ} \mathrm{C}$ to $+85^{\circ} \mathrm{C}$, and relative humidity from 0 to $95 \%$ (Gemini Dataloggers, 2017). However, the Tinytag does not provide remote real-time tracking technology, and one needs to collect the monitored data when the memory card is full. Therefore, the Tinytag data logger was only used for four of the monitored months.

The Netatmo indoor module and Tinytag were placed at a height of $1.2 \mathrm{~m}$ above the ground, and the Netatmo outdoor module was at a height of $1.5 \mathrm{~m}$ above the ground. The Netatmo anemometer was set $3 \mathrm{~m}$ above the top of the roof. The results of two monitored data sets from the Netatmo and Tinytag were able to validate each other although their hourly air temperatures, up to $0.8^{\circ} \mathrm{C}$ discrepancies. Both sets of data were used to compile a reliable set of monitored data. 


\subsection{Analysis methods}

In this work, the air temperature (AT), wet-bulb temperature (WBT) (Stull, 2011) and heat index temperatures (HT) (National Weather Service, 2019) were utilised to analyse the data. The monitored data set collected by the authors contained over a full one-year period for both outdoor and indoor microclimate data, collected in an urban setting. From this, a weather file for the year 2019 was generated containing monitored outdoor DBT, outdoor RH, wind speed, and wind direction. The WBT, dew point, and atmospheric pressure were calculated according to the monitored parameters. Solar radiation and sky cover data were duplicated from the typical weather year file due to a lack of available data set.

Two future weather files were created to investigate the thermal performance of monitored dwelling for future weather scenario as summarised in Table 1. The future weather file-1 was based on the standard typical weather year from ASHRAE, also used in other studies (Zune et al., 2020). The future weather file-2 was based on the monitored year 2019. It is important to note that the diurnal temperature variations of the future weather file- 2 were affected by UHI due to the database used for the monitored dwelling being located in the urban area of Mandalay.

The predicted temperature increments were derived from the report "Assessing the Climate Risks in Myanmar. A contribution to planning and decision-making in Myanmar: Technical Report" (ㅂorton et al., 2017) to create future weather files. The increased temperature values were predicted for 2041-2070 based on the baseline model of 1980 to 2006; therefore, the baseline years of the temperature increments and the reference weather files used in this paper were different due to the constraints of available weather data sets. The future weather file creation method was referred to the use of a "shift" of a current hourly weather data parameter, following Jentsch et al. (2008). Future weather files used in this paper were further limited due to their lack of unchanged parameters, as listed in Table 1. The future weather files used in this 
paper were created by adding predicted absolute monthly mean change value of the dry bulb temperature consistent with the reference weather files. The three seasons in Myanmar are affected by the monsoon onset time and withdrawal time; therefore, it is impossible to predict exact weeks and months for monthly mean change value. Consequently, it was assumed that each season has four months.

Table 1. Weather files used in simulations

\begin{tabular}{l|l|l}
\hline & Future weather file-1 & Future weather file-2 \\
\hline Reference weather file & A typical weather year & Monitored weather year 2019 \\
\hline Modified parameter & Dry bulb temperature \\
(the predicted increment is & $2.9^{\circ} \mathrm{C}$ for the hot season (March to June) \\
added to the reference weather & $2.4^{\circ} \mathrm{C}$ in the wet season (July to October) \\
files) & $2.8^{\circ} \mathrm{C}$ in the cold season (November to February) \\
\hline Unchanged parameters & Solar radiation, sky cover, relative humidity, wind, and precipitation \\
\hline Diurnal temperature variation & Large differences & Small differences \\
\hline Urban heat island effect & Typical weather data from airport & Monitored data from an urban dwelling \\
\hline
\end{tabular}

\subsection{Simulation experiments}

The simulations were performed using the Integrated Environmental Solution software (IES, version 2019 Hotfix1) (IESVE). IES, a commercially well-known software, specializes in building performance analysis and also qualifies as a dynamic model in the CIBSE system of model classification. ApacheSim, a dynamic thermal simulation program of IES, uses firstprinciples mathematical modelling of the heat transfer processes occurring within and around a building. MacroFlo runs as an adjunct to ApacheSim by exchanging data at run-time to achieve a fully integrated simulation of air and thermal exchanges for one weather year (IESVE, 2015).

The characteristics of the simulated dwelling, including occupant activities, internal gains, window and door operation time, and material properties, are shown in the tables below (Table 2, Table 3, and Table 4). In the simulation, the adjacent houses from the left, right and back of the monitored dwelling were also modelled; therefore, the external heat gains of the monitored dwelling were decreased due to the shading and sheltering of the adjacent houses. The elevation 
and section views are shown in Figure 7 display the front window (W1), windows from left and right sides (W2), windows at the top of the stair space (W3), front door (D1) and rear door (D2).
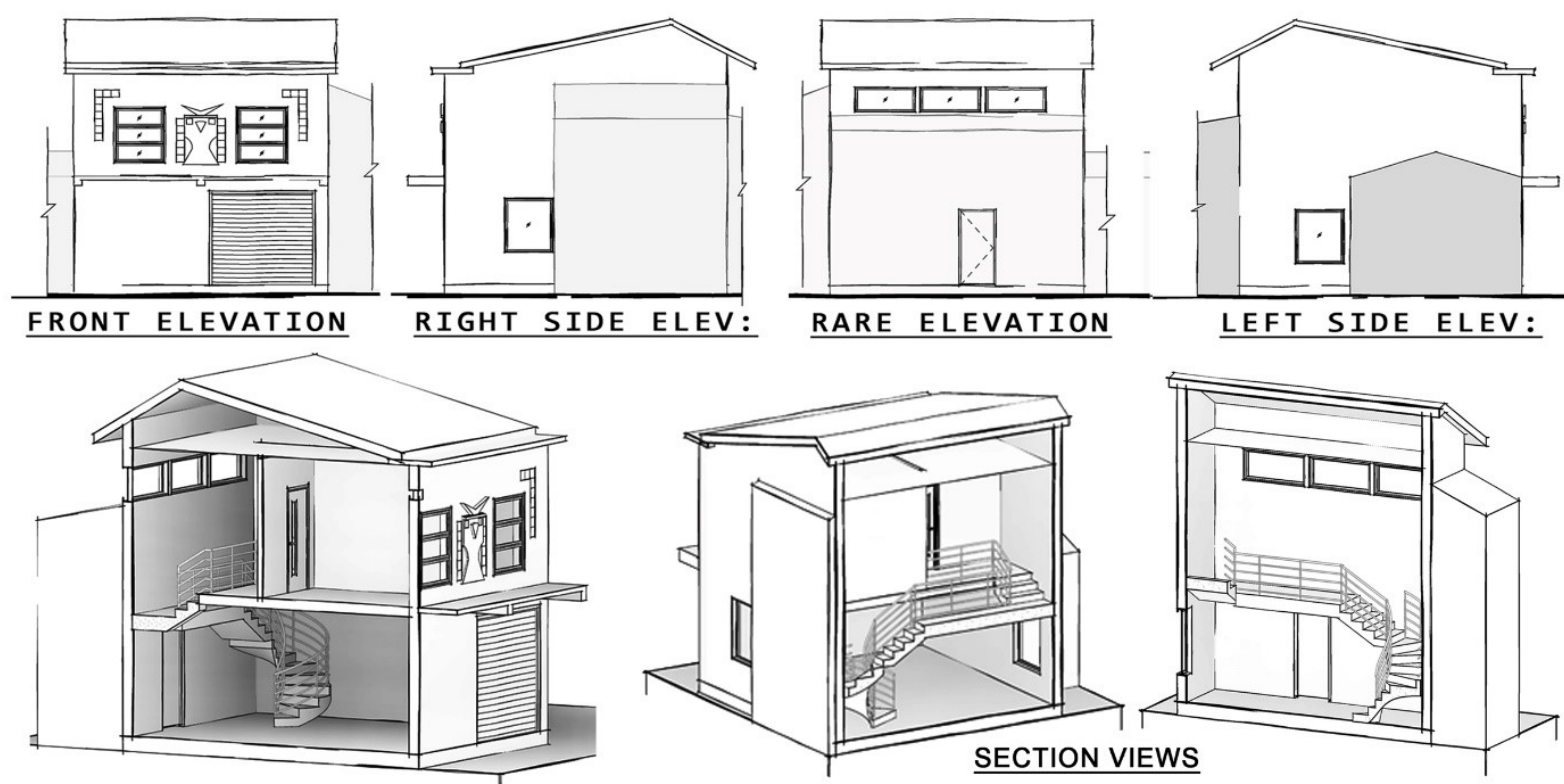

Figure 7. Elevations and section views of Mandalay dwelling

Table 2. Internal gains and schedules used in simulations

\begin{tabular}{|c|c|c|}
\hline Assumption & Description & Operation / Schedules in IES \\
\hline Occupant activities & $\begin{array}{l}\text { Three occupants }(90 \mathrm{~W} / \text { person for maximum } \\
\text { sensible gain, } 60 \mathrm{~W} / \text { person for maximum latent } \\
\text { gain) }\end{array}$ & $\begin{array}{l}\text { 06:00-09:00 am and 16:00-22:00 } \\
\text { pm in living room } \\
22: 00 \text { to 06:00 am in bedrooms }\end{array}$ \\
\hline Internal gains & $\begin{array}{l}\text { Lighting: } 8 \mathrm{~W} / \mathrm{m}^{2} \text { for sensible gain and } 8 \mathrm{~W} / \mathrm{m}^{2} \\
\text { for maximum power consumption } \\
\text { Equipment: } 5 \mathrm{~W} / \mathrm{m}^{2} \text { for sensible gain and } 5 \\
\mathrm{~W} / \mathrm{m}^{2} \text { for maximum power consumption } \\
\text { Cooking: } 10 \mathrm{~W} / \mathrm{m}^{2} \text { for sensible gain and } 10 \\
\mathrm{~W} / \mathrm{m}^{2} \text { for maximum power consumption }\end{array}$ & $\begin{array}{l}\text { Lighting: 18:00-22:00 pm } \\
\text { Equipment: } 24 \text { hours } \\
\text { Cooking: 06:00-08:00 am and } \\
\text { 16:00-18:00 pm }\end{array}$ \\
\hline Window and door & $\begin{array}{l}\text { W1: } 1.2 \times 1.5 \mathrm{~m}(80 \% \text { openable area }) \\
\text { W2: } 1.2 \times 1.5 \mathrm{~m}(80 \% \text { openable area }) \\
\text { W3: } 1.5 \times 0.7 \mathrm{~m} \times 3 \text { Nos }(60 \% \text { openable area }) \\
\text { D1: } 2.6 \times 2.6 \mathrm{~m}(90 \% \text { openable area }) \\
\text { D2: } 0.9 \times 2.1 \mathrm{~m}(90 \% \text { openable area })\end{array}$ & $\begin{array}{l}\text { W1: Closed continuously } \\
\text { W2: } 06: 00 \text { am - 22:00 pm } \\
\text { W3: Opened continuously } \\
\text { D1 and D2: } 06: 00 \text { am to } 18: 00 \mathrm{pm}\end{array}$ \\
\hline
\end{tabular}

For the simulation experiments, the 'base case' model was first built in the IES simulation engine to represent the geometries, characteristics and building envelope material properties of the monitored dwelling. The based model had some degree of thermal capacity and insulation in walls and floors, but poor insulation and less solar absorptance value in the roof. In the "testcase' model, the geometries and characteristics of the dwelling were duplicated, but the 
building envelope material properties were switched to vernacular materials, with a timber wall, timber floor, thatched roof, and high infiltration. The test-case model had a low thermal capacity and insulation in walls and floors, but high insulation and some degree of solar absorptance in the roof.

Comparison of these two cases provides an in-depth understanding of their similarities and differences in terms of thermal performance for different climate conditions. Moreover, the two cases also manifest common material choices in Myanmar housing. This comparison allows reviewing which building envelope material plays a prevailing role for overheating in extreme events, strengths and weaknesses for future weather scenarios, and even potential retrofit approaches for changing climate conditions.

Table 3. Material assumption of the monitored dwelling (CIBSE, 2015., IESVE, 2015)

\begin{tabular}{l|l|c|l|l}
\hline Components & $\begin{array}{l}\text { Description for Reference Modern Dwelling } \\
\text { in Mandalay }\end{array}$ & $\begin{array}{l}\mathrm{U} \text { Value, } \\
\mathrm{W} /\left(\mathrm{m}^{2} \mathrm{~K}\right)\end{array}$ & $\begin{array}{l}\text { Thermal } \\
\text { Capacity }(\mathrm{Cm}), \\
\mathrm{kJ} /\left(\mathrm{m}^{2} \mathrm{~K}\right)\end{array}$ & $\begin{array}{l}\text { Solar } \\
\text { Absorptance } \\
(\alpha)\end{array}$ \\
\hline Roof & Metal roof tile, roof void with ceiling & 2.6778 & 4.0176 & 0.2 \\
\hline Wall & $\begin{array}{l}13.5 \text { inches walls with cement plaster and } \\
\text { paint finish at both sides }\end{array}$ & 1.1378 & 117.00 & 0.3 \\
\hline Ground floor & Concrete slab with sand-filled below & 0.7947 & 174.72 & - \\
\hline Upper floor & Concrete slab & 2.3697 & 164.80 & - \\
\hline Doors & Aluminium door at the front, timber door at the back, timber door for internal doors \\
\hline Windows & $\begin{array}{l}\text { Opaque glazing windows with aluminium frame. Solar heat gain coefficient }=0.292 ; \text { Visible } \\
\text { transmittance = 0.76; U = 6.0058. }\end{array}$ \\
\hline Infiltration & Rough assumption for air infiltration =1.5 \\
\hline
\end{tabular}

Table 4. Material properties used in simulations, data set based on (CIBSE, 2015., IESVE, 2015)

\begin{tabular}{|c|c|c|c|c|c|}
\hline \multicolumn{2}{|c|}{ Components } & Description & U value & $\mathrm{Cm}$ & $\alpha$ \\
\hline \multirow{5}{*}{ 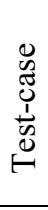 } & Roof & Thatch roof, roof void and ceiling & 0.2170 & 7.7 & 0.6 \\
\hline & Wall & Timber wall & 3.0165 & 15.6 & 0.3 \\
\hline & Floor & Timber Floor & 1.9977 & 15.6 & - \\
\hline & Others & \multicolumn{4}{|l|}{ Timber windows and timber doors } \\
\hline & Infiltration & \multicolumn{4}{|c|}{ Rough assumption for air infiltration $=15$} \\
\hline \multirow{5}{*}{ 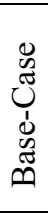 } & Roof & \multirow{5}{*}{\multicolumn{4}{|c|}{ Same as an assumption of the monitored dwelling }} \\
\hline & Wall & & & & \\
\hline & Floor & & & & \\
\hline & Others & & & & \\
\hline & Infiltration & & & & \\
\hline
\end{tabular}




\section{Results}

This section presents the analysis of the monitored and typical weather data sets, the analysis of overheating risk today (including humidity effect), and the analysis of vulnerability to extreme events today. The following section summarizes the results obtained from the monitored data sets and dynamic thermal simulations.

\subsection{Air temperatures}

Firstly, the air temperature differences between the monitored and typical weather data sets were checked, from which changes in weather without the effect of the moisture of the air can be obtained. The hourly AT of the monitored indoor and outdoor data sets for the year 2019 is shown in Figure 8. Small AT differences between the outdoor and indoor data sets shown in Figure 8 revealed that the indoor thermal environment of the monitored dwelling had a close relation to the weather outdoor. In the outdoor data for the historical weather year 2019 of Mandalay, $46.7 \%$ of a year was above DBT $30^{\circ} \mathrm{C}$, and $6 \%$ of a year was above DBT $36^{\circ} \mathrm{C}$. In the indoor data set of the monitored dwelling in $2018,55.2 \%$ of a year was above AT $30^{\circ} \mathrm{C}$ and $2.9 \%$ of a year were above AT $36^{\circ} \mathrm{C}$. More than half of the year $(55.21 \%)$ had AT above $30^{\circ} \mathrm{C}$ in the monitored indoor data set, and the numbers of warmer hours above $30^{\circ} \mathrm{C}$ in the indoor were higher than the weather outdoor. However, the numbers of warmer hours above $36^{\circ} \mathrm{C}$ in the indoor were lower than the weather outdoor.

The monitored data sets were then compared to the typical outdoor weather data in Figure 9. It was found that $28.44 \%$ of a year had AT above $30^{\circ} \mathrm{C}$ in the typical weather year data set. Therefore, comparison between the typical weather year and the monitored year revealed that the outdoor dry bulb temperature warmer hours (above $30^{\circ} \mathrm{C}$ ) in 2019 doubled compared to its baseline typical weather year from 2005 to 2013. Furthermore, the comparison for monthly temperature range showed that the time for outdoor DBT below $30^{\circ} \mathrm{C}$ was decreased (means 
DBT above $30^{\circ} \mathrm{C}$ were increased) in the monitored year 2019 compared to the typical weather year.

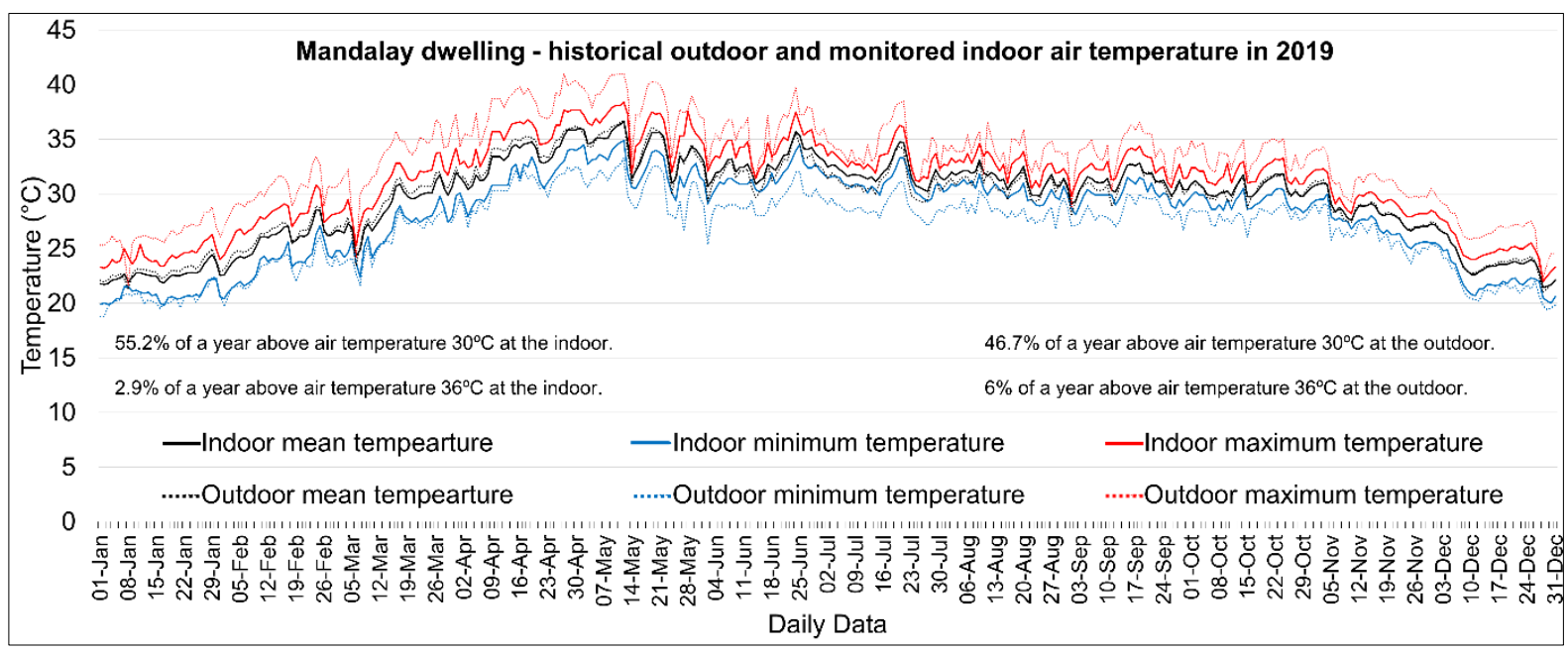

Figure 8. Monitored outdoor dry bulb temperature and indoor air temperatures in 2019, Mandalay dwelling

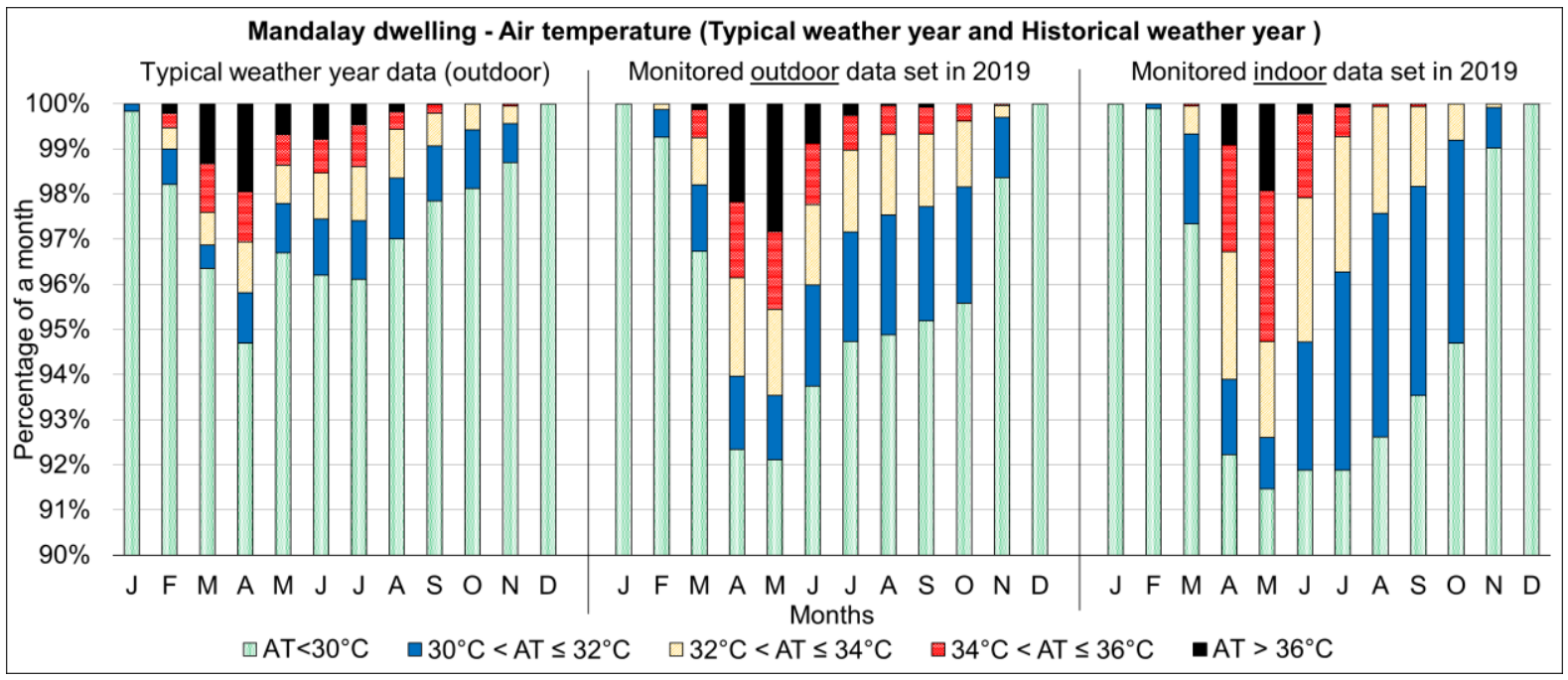

Figure 9. Temperature range of the typical and monitored year 2019 for outdoor air temperatures and monitored indoor air temperature of Mandalay dwelling

\subsection{Wet-bulb and heat-index temperatures}

WBT is widely used in the heat-stress index, and heat stress for HT can be measured based on the heat index value, in which the RH is factored in with AT. Therefore, firstly, the monthly RH was checked in Figure 10 for the typical weather year, the monitored weather year 2019 and the monitored indoor data set of Mandalay dwelling. Monthly RH results showed that RH above $75 \%$ in the typical weather year was higher than the historical weather year 2019 
throughout a year. The percentage of a year above RH 75\% was decreased in the year 2019 compared to the typical weather year. The RH in 2019 rarely reached $90 \%$ humidity.

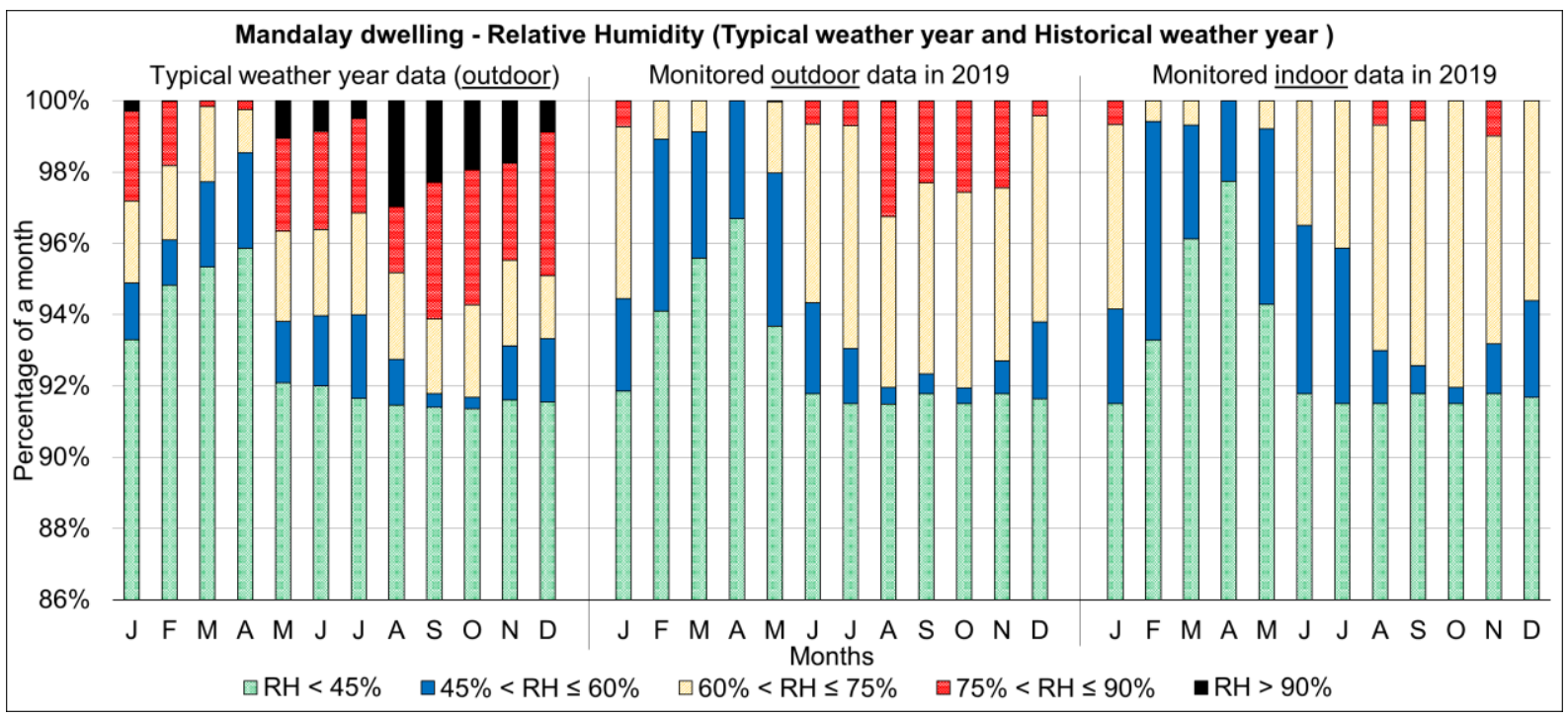

Figure 10. Monthly relative humidity from a typical weather year for outdoor and a monitored weather year 2019 for indoor and outdoor for Mandalay dwelling

Although the year 2019 was drier than the baseline typical weather year, the effect of RH on WBT and HT were found due to increased AT. Furthermore, different ranges of high WBT and HT were found once the monsoon onset time had started. In Figure 11, the outdoor WBT above $25^{\circ} \mathrm{C}$ were significantly increased from April to November due to increased monthly temperatures in 2019. Similar results were found in the 2019 indoor data set. To note that the DBT above $30^{\circ} \mathrm{C}$ was increased in 2019 , but the $\mathrm{RH}$ above $75 \%$ were decreased. Therefore, both the WBT and HT were increased in 2019. Figure 12 showed that the percentage of a month for a high HT were higher in 2019 compared to the typical weather year. In 2019, the HT reached 'a danger stage' from April to October in the outdoor data set, and "an extreme caution stage" from May to October in the indoor data set. 


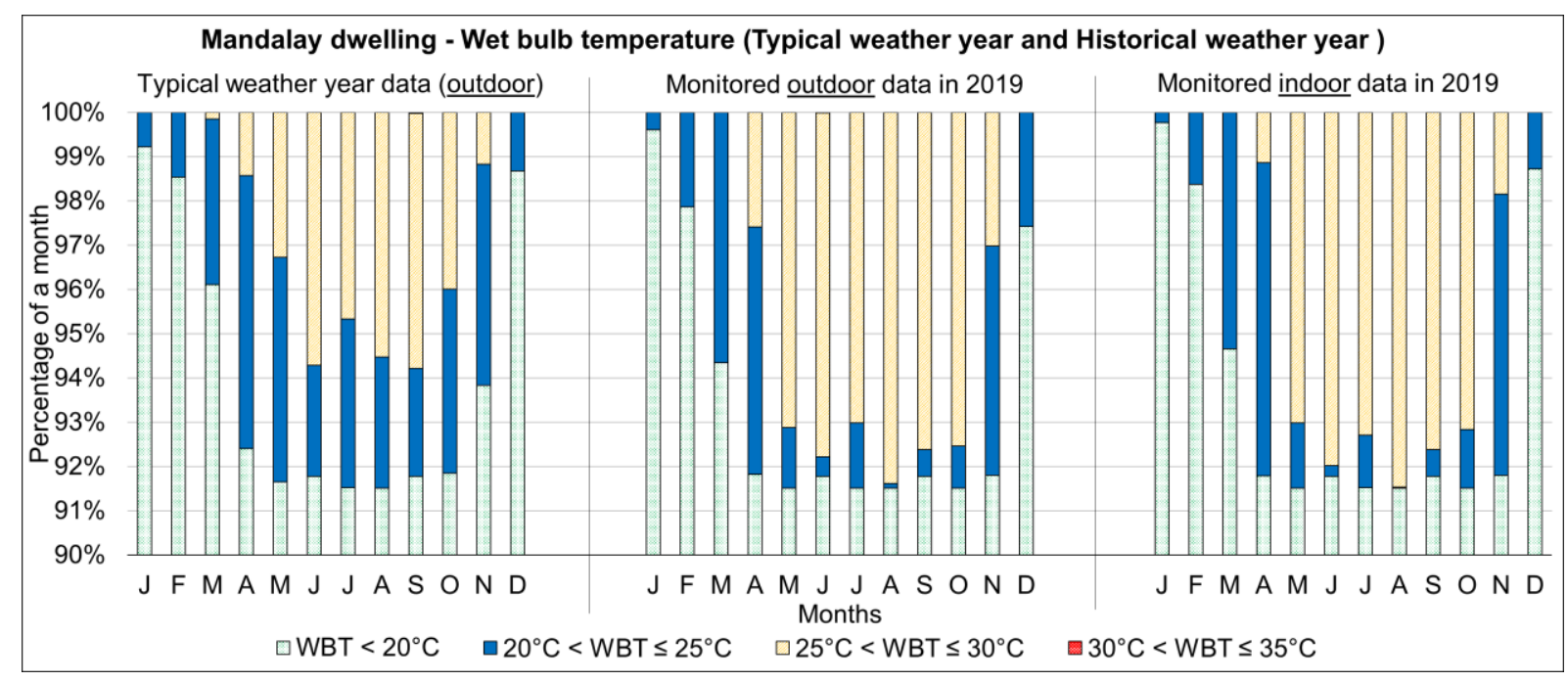

Figure 11. Wet-bulb temperature range of a year in a typical and monitored weather year data sets for outdoor and indoor, Mandalay dwelling

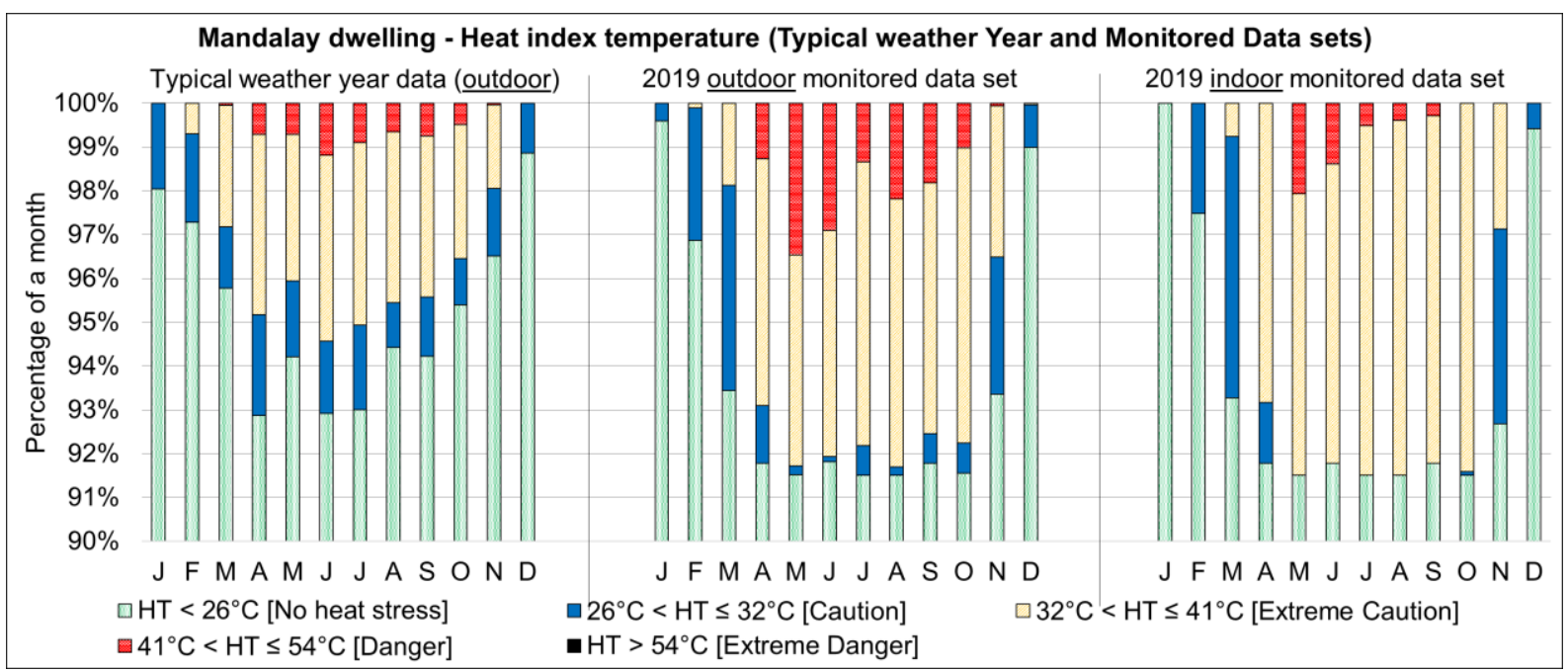

Figure 12. Heat index temperature range of a year in a typical and monitored weather year data sets for outdoor and indoor, Mandalay dwelling

Figure 13 presents the proportion of WBT and HT for a year. The typical weather year maintained $31.7 \%$ of the year for the WBT above $25^{\circ} \mathrm{C}$, and $5.49 \%$ of a year reaching the 'danger' heat stress levels. In the outdoor weather of the year 2019, a total of 51\% was above WBT $25^{\circ} \mathrm{C}$, and there were $14.06 \%$ of a year reaching 'danger' heat stress levels. The indoor monitored data set showed that $48,5 \%$ of the year 2019 was above WBT $25^{\circ} \mathrm{C}$, and there were $4.65 \%$ of a year with a 'danger' stage heat stress condition. The proportion of WBT below $20^{\circ} \mathrm{C}$ was decreased in the year 2019 compared to the typical weather year. The proportion of 'no heat stress' stage was decreased in the year 2019 compared to the typical weather year. For the 
outdoor condition, there were $43.53 \%$ of a year with 'no heat stress' stage in the typical weather year, but there were only $23.72 \%$ of a year with 'no heat stress stage' in the year 2019 . Therefore, the proportion of 'no heat stress' stage for the indoor condition in 2019 was also decreased.

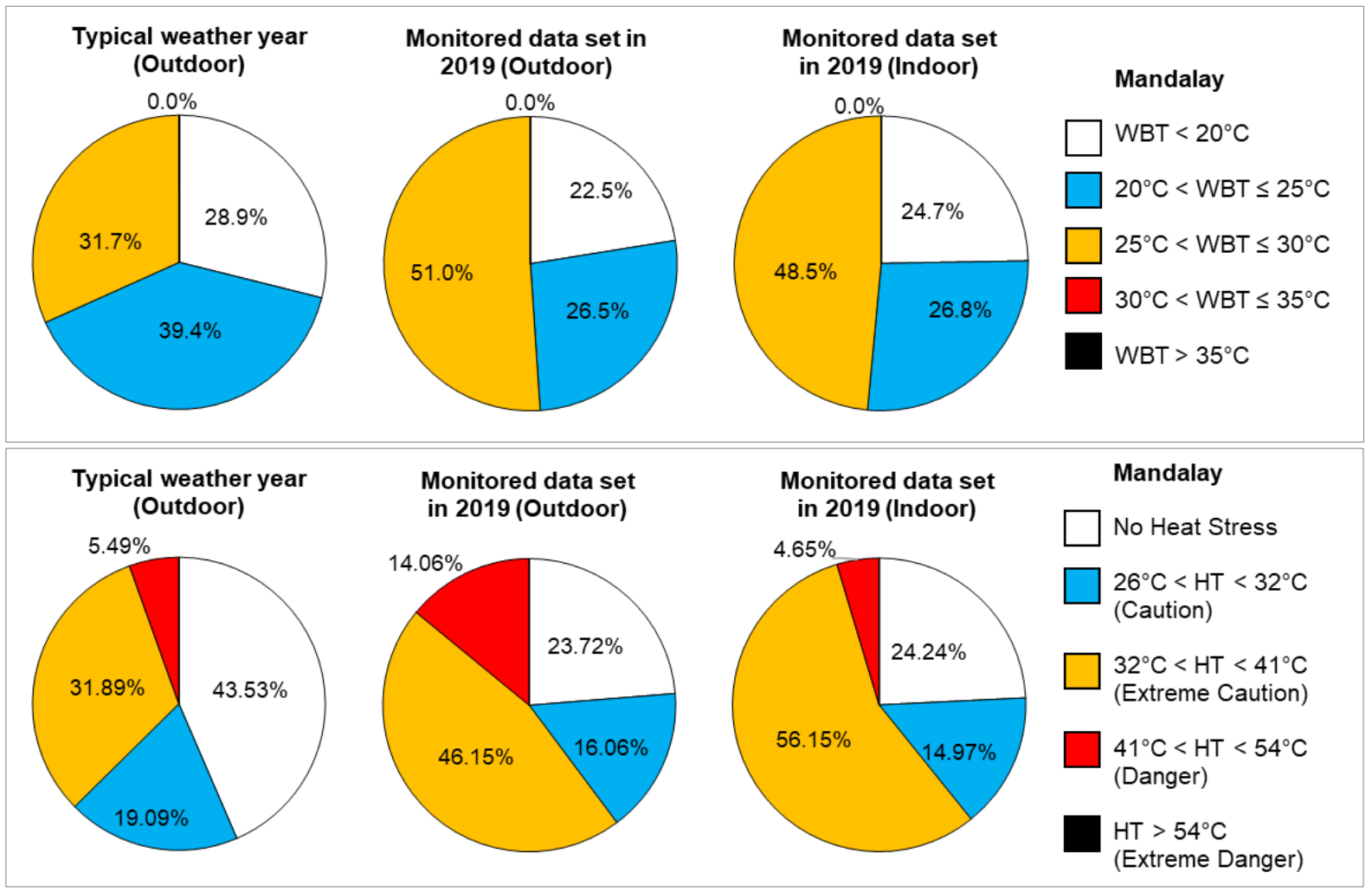

Figure 13. Proportion of heat index temperature and wet-bulb temperature in a typical and monitored weather year data sets for indoor and outdoor, Mandalay dwelling

Comparisons between yearly and monthly results of the monitored and typical weather data sets showed that there were increments in WBT and HT. Therefore, their intensity on the peak days of each season in 2019 was checked in Figure 14. In the monitored indoor data set, the highest AT of $38.4^{\circ} \mathrm{C}$ was found on the $12^{\text {th }}$ of May and of $33.9^{\circ} \mathrm{C}$ was found on the $11^{\text {th }}$ of August. However, their HT on those days was similar different due to a combined effect of AT and RH. The HT reached $44.83^{\circ} \mathrm{C}$ on the $12^{\text {th }}$ of May and also reached $43.63^{\circ} \mathrm{C}$ on the $11^{\text {th }}$ of August. As the RH of December was not as high as August, the HT of the $1^{\text {st }}$ of December was $29.78^{\circ} \mathrm{C}$ on the $1^{\text {st }}$ of December. The WBT reached $27.51^{\circ} \mathrm{C}$ on the $12^{\text {th }}$ of May $28.2^{\circ} \mathrm{C}$ on the $11^{\text {th }}$ of August and $22.31^{\circ} \mathrm{C}$ on the $1^{\text {st }}$ of December. Significant differences between the outdoor 
and indoor RH were found; therefore, the combined effect of hourly AT and RH were caused differences between the weather outdoor and the indoor thermal environment.

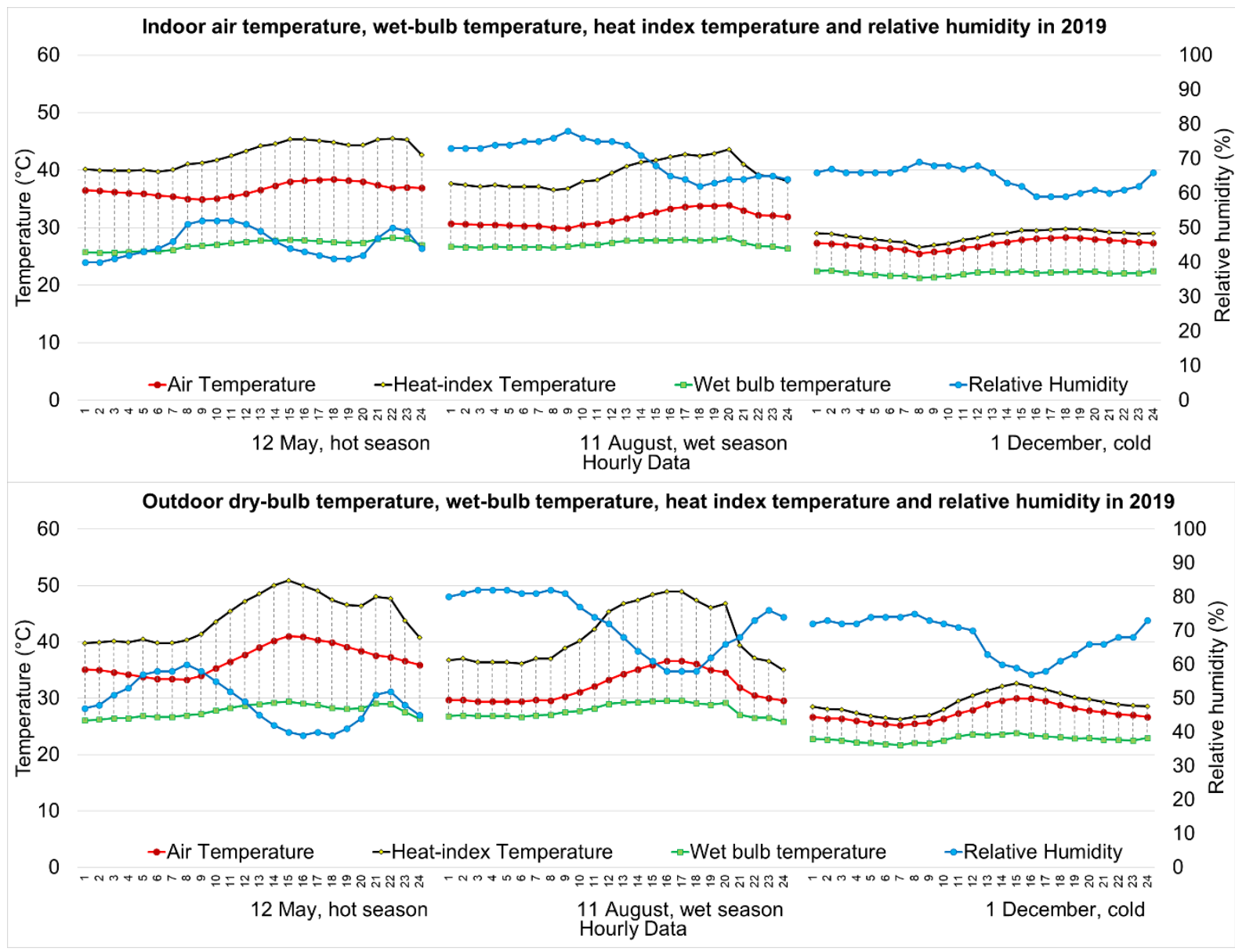

Figure 14. Monitored indoor and outdoor hourly temperature, wet-bulb temperature, heat-index temperature and relative humidity in 12 May, 11 August and 1 December in 2019, Mandalay dwelling

\subsection{Simulation validation}

A comparison between the monthly variations of the dry bulb temperatures of the typical weather year data and the 2019 monitored data sets for indoor and outdoor was presented in this section. The monsoon onset and withdrawal time can be tracked by checking the monthly AT and RH changes (Figure 15). In the typical weather year, when the monsoon onset time came in May, the monthly AT was dropped but the RH was increased. In 2019, the monsoon onset time came late; therefore, the marked changes in monthly $\mathrm{AT}$ and $\mathrm{RH}$ were found in June. When the monsoon arrived, the lower extreme of DBT dropped about $20^{\circ} \mathrm{C}$ in the typical weather year, but was maintained above $25^{\circ} \mathrm{C}$ in the monitored year 2019 . 
The upper and lower extremes of DBT were greater in the typical weather year than the monitored year 2019. Shorter lengths of upper quartile and lower quartile throughout the year were found in the monitored outdoor and indoor data sets, and their monthly median values were also higher than the typical weather year. The results of monthly median values and length of quartiles revealed that the annual and monthly mean temperatures were increased in the monitored year 2019 compared to the typical weather year. Moreover, the values of annual and monthly mean RH were dropped in the monitored year. Overall, the monitored year 2019 was drier and warmer than the typical weather year, and had a smaller diurnal temperature swing.

The discrepancies in AT between the monitored indoor data set and the results of based simulation model were noticeable. For instance, in April, in the monitored indoor data set, the monthly median value was $28.8^{\circ} \mathrm{C}$ and the highest AT was $34.2^{\circ} \mathrm{C}$. On the other hand, in April, the monthly median value was $29.8^{\circ} \mathrm{C}$ and the highest AT was $36.5^{\circ} \mathrm{C}$ in the simulation model. It was also found that the discrepancy on the RH between the simulation model and monitored data sets were even more obvious, especially from June to December. Change in heat store in a building results in a combination of solar heat gain, ventilation heat gains or loss, evaporative heat loss, internal heat gains and conduction heat gain or loss (Szokolay, 2008, p35). During the monsoon period, the indoor humidity increased when the hot, humid air was brought inside. In the simulation model, the window $\mathrm{W} 3$, which is at the top of the stair space, was opened throughout the year. This was accounted for in the simulation models as high humidity was maintained both from the supply humid air and the internal moisture gains. In the actual condition, closing the windows during a high humidity period (e.g. when it rains) also could prevent moisture from entering to the dwelling. Therefore, the discrepancies could be due to the impacts of air infiltrations, internal gains, occupant behaviours for door and window opening times; while assumptions were made for these in the simulation models, exact situations in real-world scenarios could be different. Nevertheless, it can be considered that the 
simulation model had a reasonably good agreement with the monitored indoor data set and the trends were observed to be similar.



Figure 15. Monthly air temperature and relative humidity from a typical weather year, monitored data sets (outdoor and living room) and simulation model (living room)

\subsection{Future weather scenarios}

This section presents the analysis of overheating risk and vulnerability to extreme events in the future for the selected building envelopes. Similar analyses were undertaken to compare the impacts of the two-building cases on different weather scenarios. The number of days and the hourly percentage of a year in which indoor AT exceeded $30^{\circ} \mathrm{C}$ and $36^{\circ} \mathrm{C}$ are shown in Figure 16, from the results of the two cases for the monitored year 2019 and two future weather files. The results between the two cases indicate that the base model maintained fewer days, 
but more hours that exceeded the indoor AT of $30^{\circ} \mathrm{C}$ and $36^{\circ} \mathrm{C}$, compared to the outdoor weather; the test-case model maintained more days and more hours exceed the indoor AT $30^{\circ} \mathrm{C}$ and $36^{\circ} \mathrm{C}$, compared to the outdoor weather. The results between the two future weather files found that the future weather file-1 caused a greater number of days, but a less hourly percentage of the year exceeding the indoor AT of $30^{\circ} \mathrm{C}$ and $36^{\circ} \mathrm{C}$ compared to the future weather file-2.

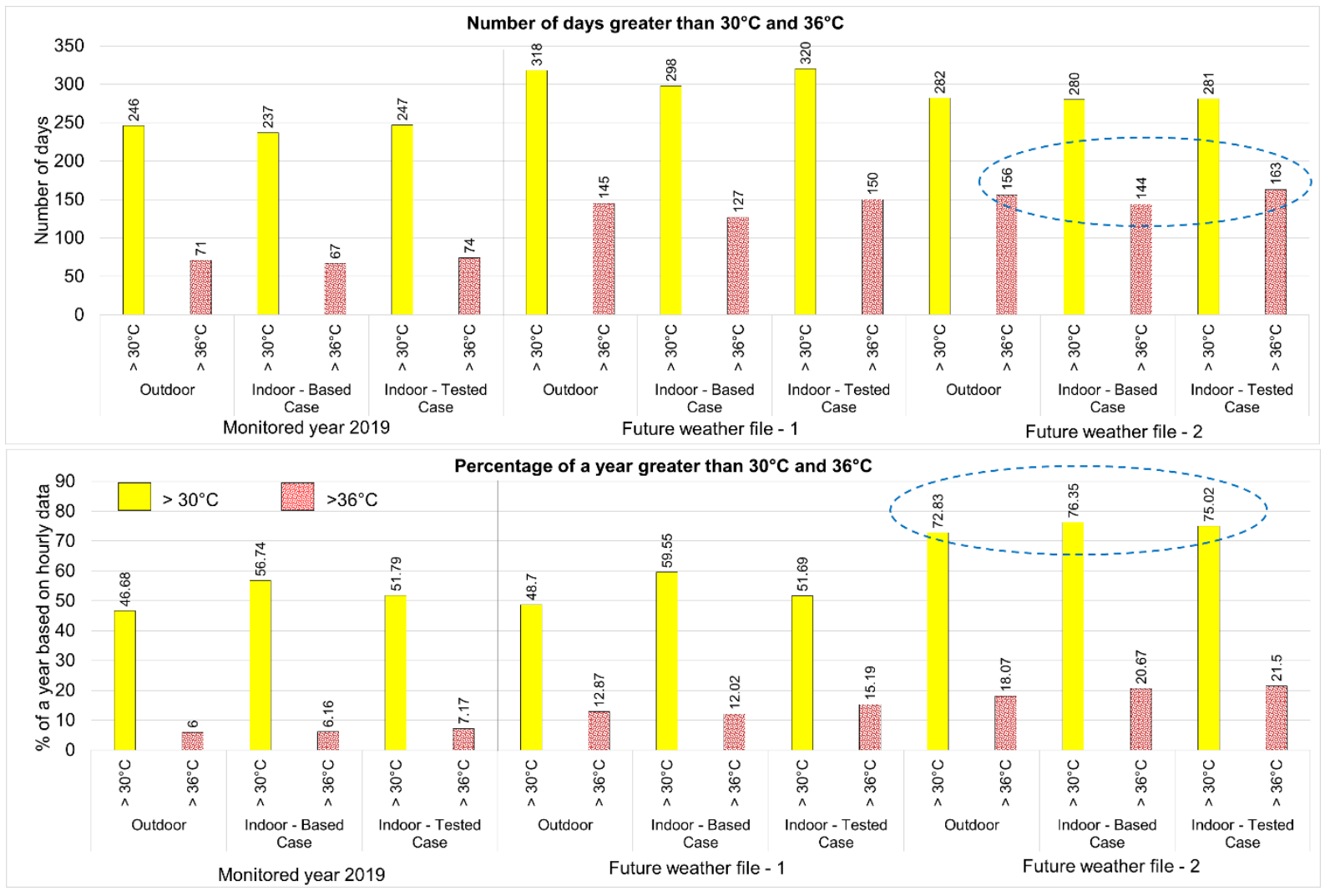

Figure 16. Simulated air temperatures in Mandalay dwelling (living room) - annual values

The monthly variations of the outdoor and indoor temperatures for the two cases for the monitored year 2019 and two future weather files were checked, and the results are shown in Figure 17. It was observed that there were large differences between the lower and upper extremes in the future weather file-1, due to its reference to the typical weather data. There was a large diurnal temperature swing in the typical weather year, which are shown in Figure 15. As future weather file-1 was based on the typical weather year, there were also large diurnal temperature swings in the future weather file- 1 . 
Unlike the typical weather year, the monitored weather year data contained UHI and small diurnal temperature swing, from which the future weather file- 2 was created. That could be a reason to cause smaller diurnal temperature swings in both results of the monitored year 2019 and the future weather file-2. Moreover, the results of future weather file-2 showed relatively increased values against the monitored weather year 2019. The results of the base-case model showed a smaller diurnal temperature swing than the test-case model for all months throughout a year in both future weather files.

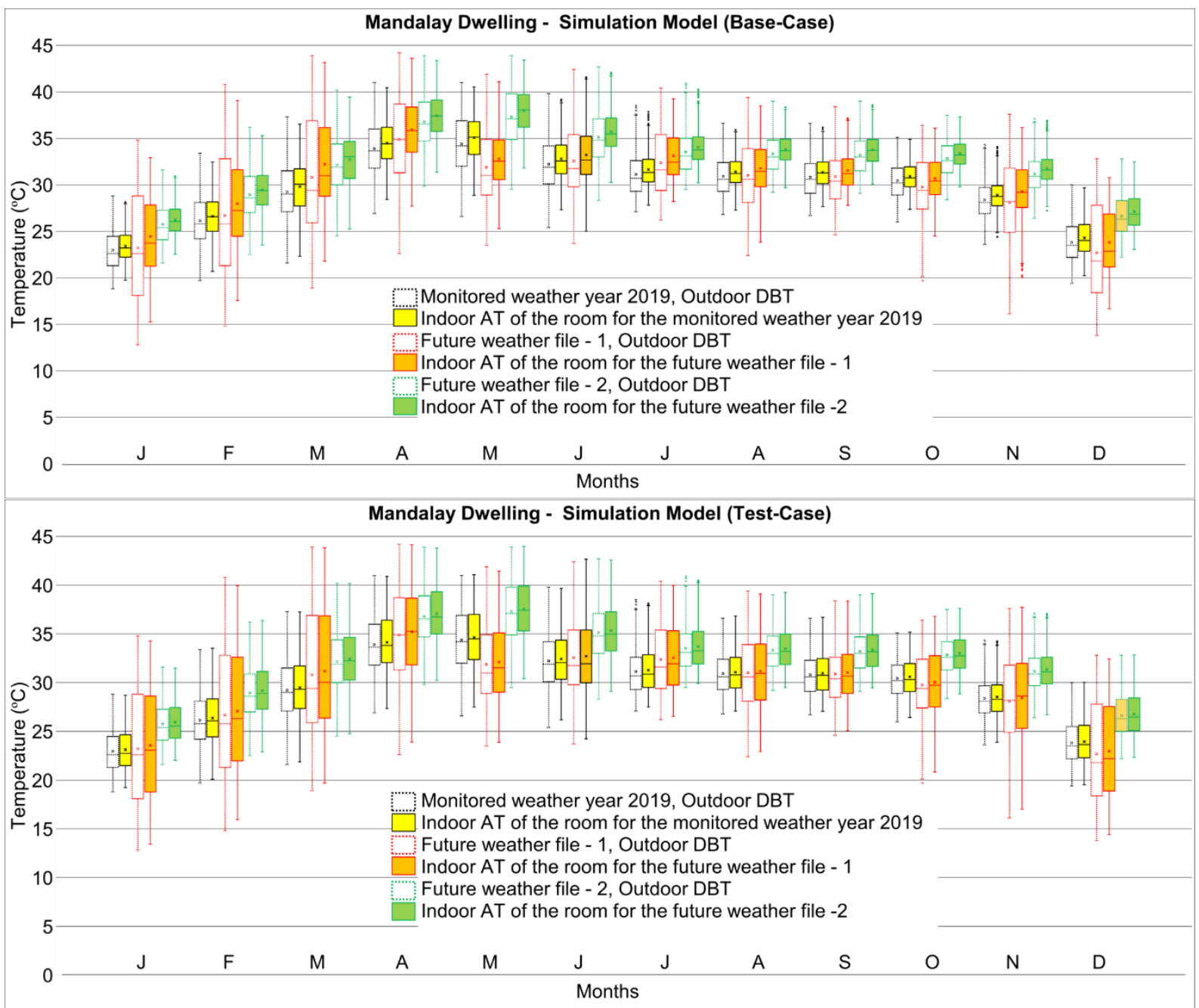

Figure 17. Simulated air temperatures in Mandalay dwelling (living room) - monthly values 


\section{Discussion}

This section presents the findings of the monitored data sets analysis, and discusses the impacts of changes in weather, the performance of base-case and test-case envelopes, limitation of the study and suggested future work.

\subsection{Typical weather data and monitored weather data}

Empirical data, informs evidence-based solutions based on observed and measured phenomena, is vital for a comprehensive knowledge of the local context and translating theory into real practical applications. The results of the monitored data sets had a good agreement with the "Myanmar Climate Report" (Aung et al., 2017) because there were changes in monsoon onset and withdrawal time in 2019. Changes of monsoon have a strong impact on the summertime high temperatures, and the heat stress which occurred in the rainy season. Although there were no extreme heatwave events and considerable high temperatures in the monitored year (unlike the 2010 heatwave), the results found that the warmer hours (above $30^{\circ} \mathrm{C}$ ) in 2019 doubled compared to its baseline typical weather year.

UHI and variation between the urban and rural areas cause uncertainties in the building thermal performance design. The vertical length of Myanmar is about two times longer than the United Kingdom, and its area is 2.5 times larger, but its population is slightly lower. Thus, national population density is much lower than in the United Kingdom, but while rural areas have very low population density, urban areas are often highly overcrowded, and predisposed to UHI. The results of the Mandalay dwelling may not be representative of all dwellings in urban and rural areas of Myanmar, because the temperature of an urban area can be significantly warmer than its surrounding rural areas, and the temperature intensity varies on a case-by-case basis. UHI and the impacts of adjacent buildings on the microclimate of the monitored dwelling were excluded from the simulations. The outdoor weather was monitored just outside of the dwelling in a highly urbanised area, thus the results of small diurnal 
temperature swing between outdoor and indoor data sets could be due to UHI. Both external and internal temperature swings play a role to design the building envelope.

In this work, the HT was used in order to understand the impacts of humidity on the warm air temperature, but the heat index equation is not directly applicable to a free-running condition. The adaptive thermal comfort method enables the use of natural ventilation, while the heat balance method discourages it; moreover, people adapt to the temperatures within buildings, and they adapt the buildings themselves to suit their own thermal preferences (Roaf and Nicol, 2017). The monitored room contained one opening on each side of the wall, and the opening time of the doors and windows could be varied by the occupants throughout the year, depending on the seasons. Although the database behind the heat index equation and the condition of the dwelling was not calibrated, according to the results for the monthly variations of HT which were calculated from the monitored data sets, it can be understood that there might have a strong impact on the heat stress during the rainy season.

\subsection{Performance of the base-case envelope}

The base-case model, a model contained material assumptions of the monitored dwelling, represented the use of thermal capacity in walls and floors but poor roof insulation. The thermal capacity of the base-case model's wall was 7.5 times higher than the test-case model. Similarly, the thermal capacity of the base-case model's ground floor was 2.5 times higher than the testcase. The use of high thermal capacity is only effective when the nocturnal temperature noticeably drops from daytime norms, on the other hand, it is effective when the daytime temperatures reach their peak in summer.

In the monitored outdoor data set, there were small diurnal temperature swings throughout a year. However, although the peak outdoor AT reached above $41{ }^{\circ} \mathrm{C}$ in April and May in the monitored outdoor data set, the peak indoor AT only reached above $37.7^{\circ} \mathrm{C}$ in April and $38.4^{\circ} \mathrm{C}$ May in the monitored indoor data set. (Figure 15). In Figure 4, it was noted that adding sun 
shading of a window was effective to improve passive cooling, and it could be more effective if all the external walls also had sun shading. With this in mind, firstly, $1.5 \mathrm{~m}$ width horizontal sun shading was added in the base-case model, named it as 'base-case with window shading'. There were very small differences between the base-case model and base-case with windowshading only. Therefore, $1.5 \mathrm{~m}$ width horizontal sun shading was added along the ground level wall and upper-level wall; that was named as 'base-case with wall shading'. As a result, a total of 21 hours $\left(0.24 \%\right.$ of a year) for the indoor air temperature above $36^{\circ} \mathrm{C}$ were decreased in 2019 by adding sun shading.

In the future weather scenario, for instance, the results of the base-case model (without sun shading) for the future weather-2 (Figure 16) showed that there were 144 days above indoor AT $36^{\circ} \mathrm{C}$ while there were 156 days above outdoor DBT $36^{\circ} \mathrm{C}$. However, there were $76.36 \%$ of a year above indoor AT $30^{\circ} \mathrm{C}$ while there were $72.83 \%$ of a year above outdoor DBT $30^{\circ} \mathrm{C}$. The annual mean outdoor DBT for the future weather file-2 is $32.2^{\circ} \mathrm{C}$. Therefore, the results of this work (both the monitored data sets and simulation results) demonstrated that if buildings have some degree of thermal capacity in its walls, this will protect against extreme outdoor temperatures, but it is also likely to maintain a high mean air temperature throughout the year.

\subsection{Performance of the test-case envelope}

The test-case model represented the use of a relatively lower thermal mass in walls and good insulation in roofs. Similar to the base-case model, $1.5 \mathrm{~m}$ width horizontal sun shading for all the exterior walls was added in the test-case model. In this case, the shading resulted in a decrease of 110 hours $(1.26 \%$ of a year $)$ of the indoor air temperature above $36^{\circ} \mathrm{C}$ in 2019 .

In the future weather scenario, for instance, the results of the test-case model for the future weather-2 (Figure 16) showed that there were 163 days above indoor AT $36^{\circ} \mathrm{C}$ while there were 156 days above outdoor DBT $36^{\circ} \mathrm{C}$. However, there were $75.02 \%$ of a year above indoor AT $30^{\circ} \mathrm{C}$ for the test-case model while there were $76.35 \%$ of a year above indoor AT $30^{\circ} \mathrm{C}$ for 
the base-case model. The results presented here are in agreement with the study (Nicol et al., 2005): if buildings have poor insulation characteristics or are lightweight, with low thermal capacity, they are likely to produce uncomfortable indoor temperatures during hot summers. Again, the results of this paper also found a classic dilemma to choose a heavyweight or lightweight building envelope, coupled with the cooling effect of air movement in the warmhumid climate houses (Szokolay, 2000). Both heavyweight materials (base-case) and lightweight materials (test-case) have both advantages and disadvantages in the tropics, in terms of their response for extreme heatwave events and typical tropical weather, and this makes it difficult to make one selection.

\subsection{Limitations and future work}

It is important to note that all simulation results contained general estimates of air infiltration and internal heat gains, and a simplification of window and door opening time and occupant behaviour in terms of thermal comfort adaptation. The discrepancies between the monitored indoor data set and the results of the simulation model were noticeable and proven to be a result of the weather data set used, which was the recommended data for this kind of work. Therefore, a need for better data and careful consideration of its limitation was found to be crucial.

Another constraint of the thermal comfort study for Myanmar is unknown values for thermal neutrality for free-running buildings; this also relates to the way in which overheating is defined. Nevertheless, both from the monitored indoor data set and the results of the simulation model (base-case), it can be understood that the monitored dwelling was not able to provide thermal comfort throughout the year, and there were high overheating risks through its close response to the outdoor climate. Whilst the monitored dwelling may not be representative of all modern dwellings in Myanmar, it does represent the fundamental construction materials used and the building envelope performance for the studied climate. Despite these limitations, 
the findings of this study represent a substantial body of information for the monitored weather year and the importance of occupant behaviour for adaptive thermal comfort.

The integration of vernacular strategies in Myanmar housing seems to have remained remarkably resilient and are still the norm even in modern dwellings, but the use of building material has been changed. Here, the building envelope material variation in two cases manifest the common material choices in Myanmar housing. Notably, that meant there was a high Uvalue for the roof of the base-case model but a low U-value for the test-case model. Also, there was a high reflectivity for the roof of the base-case model but a low reflectivity for the roof of the test-case model. Furthermore, both base-case and test-case models contained different thermal properties for wall and floor materials. Therefore, the impacts of building envelope materials on the dwelling were not certain. However, A simulation study for Myanmar climates shows that adding insulation to the roofs at first is better than adding insulation (and thermal mass) in walls and floors (Zune et al., 2018). Furthermore, the indoor temperatures can be reduced by using high reflectivity, low solar absorptivity roofs. Although a light, cool-colour surface is suggested to reduce solar absorption and the exterior surface temperature, it also could result in a considerably high risk of condensation because mould will grow on substrates where the surface relative humidity is at or above $80 \%$. Figure 10 showed that more than $4 \%$ of a year in the year 2019 was above the RH $80 \%$ at the outdoor. As the RH above $80 \%$ for the indoor thermal environment was less than $1 \%$ of a year, this result showed that the differences in internal surface temperatures of the building envelope will pay an important role in determining whether surface condensation and mould growth will occur as a consequence of offsetting temperatures against the weather outdoor. The finding of this study further contributed that the use of thermal capacity and insulation for walls have both advantages and disadvantages for extreme scenarios and year-round thermal comfort for Myanmar climate. In this regard, further studies are needed to investigate not only how to achieve a greater thermal 
comfort from a combine passive strategy using ventilation, shading, and building envelope thermal performance effectively but also to avoid mould growth and condensation.

The passive design techniques used in Myanmar vernacular housing such as pitched roofs with wide eave projections, verandas, and semi-outdoor spaces, raised floors (Zune et al., 2020) were not included in the studied dwelling presented in this paper. Some passive design such as raised floor seems to have disappeared in modern dwellings in Myanmar. For the climate of Mandalay, the psychrometric charts showed that the use of shading and natural ventilation have more advantages for passive cooling compared to thermal mass. In this study, it was found that the effect of shading was more significant for the building with high U-value (test-case model). Wall shading is preferable to protect the solar gain for the whole building envelope. As the usefulness of shading and natural ventilation can be varied by building orientation and other design parameters, further research is needed in that respect.

The results of the thermal performance prediction were limited by the quality of the future weather files. The weather data, whether generated either from a long-period database or from a few recent years, is a key source to predict building thermal performance design for a changing climate condition. The wind data obtained from the Netatmo anemometer was limited for wind microclimate assessment due to its location of an urban setting. Moreover, the solar radiation data used in the weather files were from satellite data. Therefore, there is a need to make climate data more accessible, which could assist research organizations and regulation and standards-setting bodies in providing their responses to climate change. Further research on shading design, natural ventilation for passive cooling, and occupant behaviour for adaptive thermal comfort are essential to quantify their impacts on the building thermal performance of free-running modern dwellings, which were left in this paper. For those studies, the thermal threshold for naturally ventilated buildings in Myanmar climate is crucial, for which further research is needed. 


\section{Conclusion}

Using empirical data sets and simulations, the building thermal performance study in this paper pieced together an understanding of how the climate affected the performance of the observed buildings. Regarding the building thermal prediction for future climate scenarios, the simulation experiments were carried out for validation and building thermal performance prediction for two different building envelopes. At the outdoor weather condition, in terms of DBT alone, the results found that the warmer hours above $30^{\circ} \mathrm{C}$ in 2019 doubled compared to its baseline typical weather year. The effect of monthly RH changes between a typical weather year and monitored year 2019 was found in the monthly results of WBT and HT due to the increased DBT. In terms of heat stress, $14.06 \%$ of a year were found as a 'danger' heat index temperature stage in 2019 while there were only 5.49\% in the typical weather year data. At the indoor condition, the indoor thermal environment the monitored dwelling performed closely to the weather outdoor, but there were considerable offsets for the daily peak temperatures and humidity. In essence, the findings indicated that free-running (modern) dwellings in Myanmar face two fundamental challenges for thermal comfort: high vulnerability to extreme heatwave events, and underperformance for increased heat index temperature.

Using a single database with limited assumptions in simulations, it is impossible to determine which design inputs are relatively more effective to improve the thermal performance of Myanmar dwellings in response to extreme summer overheating and to achieve year-round thermal comfort in future climate scenarios. Although the in situ monitored datasets and simulations were limited, the findings of this study contribute valuable insights as follows.

- An understanding of the vulnerability of homes to overheating in Myanmar, particularly from the impact of climatic elements on thermal comfort: the findings showed evidence of the health risks in Myanmar in terms of heat stress which is accessed using wet-bulb and heat index temperatures. 
- An understanding of the impacts of changes in monsoon onset and withdrawal time, warmer night temperatures, and the urban heat island effect on the indoor thermal environment: the results of the analysis showed how the combined effect of air temperature and humidity can be changed in future climate scenarios compared to the typical weather year and the historical weather year 2019.

- An understanding of the material property selection for the Myanmar climate: the study compared the impacts of heavy and lightweight building materials in Myanmar climates in terms of their different capability to offset the extreme temperatures and adjust daily mean temperatures, and also discussed the effect of humidity in the study climates.

Myanmar is still a country with a poor health care system, inadequate legislation, and limited research about thermal performance building design. Nevertheless, the country is exposed to the global risks of climate change, and as a tropical country, it is particularly vulnerable to some of these. This paper is a part of individual research that intends to investigate thermal performance assessment of buildings, both for vernacular and modern constructions in Myanmar. On the national scale, Myanmar needs systematic and comprehensive research for building thermal performance design, both for short-term and longterm changing climate conditions. Further studies are necessary analysing large monitoring data sets with more rigour for validation of building thermal performance for various built forms and different building types that will create a more robust evidence base for use in sustainable designs adapted to future climate scenarios. 


\section{Acknowledgements}

The authors gratefully acknowledge the homeowners of the monitored dwelling for their agreement and help of the field measurements, and the University of Nottingham for the Netatmo equipment.

\section{Reference}

ASHRAE (2010) ASHRAE 55-2010: Thermal environmental conditions for human occupancy. Atlanta. American Society of Heating, Refrigerating and Air-Conditioning Engineers, Inc.

ASHRAE (2013) ANSI ASHRAE Standard 55: Thermal environmental conditions for human occupancy. USA. American Society of Heating, Refrigerating and Air-Conditioning Engineers, Inc.

Aung, Lai Lai., Zin, Ei Ei., Theingi, Pwint., Elvera, Naw., Aung, Phyu Phyu., Han, Thu Thu., Oo, Yamin \& Skaland, Reidun Gangsto In: (2017) Myanmar climate report. In. MET report, DMH (Yangon).

Bansal, Ben., Fox, Elliott \& Oka, Manuel (2015) Architectural guide Yangon. Berlin, DOM Publishers.

BSI (2006) BS-EN-ISO-7730:2005: Ergonomics of the thermal environment: Analytical determination and interpretation of thermal comfort using calculation of the PMV and $P P D$ indices and local thermal comfort criteria London. British Standard Institute.

Busch, J. F. (1990) Thermal responses to the Thai office environment. ASHRAE Transactions, 96, (1) 859-872.

Chapman, Lee., Bell, Cassandra \& Bell, Simon (2017) Can the crowdsourcing data paradigm take atmospheric science to a new level? A case study of the urban heat island of London quantified using Netatmo weather stations. International Journal of Climatology, 37, (2017) 3597-3605. DOI: 10.1002/joc.4940.

CIBSE (2014) TM55: Design for future climate: case studies. London. The Chartered Institution of Building Services Engineers.

CIBSE (2015) GVA/15 CIBSE Guide A: Environmental design 2015. Lavenham, Suffolk, UK. Chartered Institution of Building Services Engineers.

Costello, A.., Abbas, M.., Allen, A.., Ball, S.., Bell, S.., Bellamy, R.., Friel, S.., Groce, N.., Johnson, A.., Kett, M.., Lee, M.., Levy, C.., Maslin, M.., McCoy, D.., McGuire, B.., Montgomery, H.., Napier, D.., Pagel, C.., Patel, J.., Oliveira, J.A.P. de., Redclift, N.., Rees, H.., Rogger, D.., Scott, J.., Stephenson, J.., Twigg, J.., Wolff, J. \& Patterson, C. (2009) Managing the health effects of climate change. Lancet and University College London Institute for Global Health Commission, 373, (9676) 1693-1733. DOI: 10.1016/S0140-6736(09)60935-1.

deDear, Richard J. \& Brager, Gail S. (2002) Thermal comfort in naturally ventilated buildings: Revisions to ASHRAE standard 55. Energy and Buildings, 34, (2002) 549-561. DOI: 10.1016/S0378-7788(02)00005-1.

deDear, Richard J.., Leow, K. G. \& Foo, S. C. (1991) Thermal comfort in the humid tropics: Field experiments in air conditioned and naturally ventilated buildings in Singapore. International Journal of Biometeorology, 34, (4) 259-265. DOI: 10.1007/BF01041840 
Eckstein, David., Kunzel, Vera., Schafer, Laura \& Winges, Maik (2019) Global climate risk index 2020. Who suffers most from extreme weather events? Weather-related loss events in 2018 and 1999 to 2018. Bonn, Germany, Germanwatch e.V.

Falconer, John., Moore, Elizabeth., Kahrs, Daniel., Birnbaum, Alfred., Corocco, Virgeinia Mckeen Di \& Cummings, Joe (2000) Burmese design \& architecture (Photography by Luca Invernizzi Tettoni). Singapore, Petiplud Editions (HK).

Forwood, B. (1995). What is thermal comfort in a naturally ventilated buildings? In: Nicol, F.., Humphreys, M.., Sykes, O. \& Roaf, S. (eds.) Standards for thermal comfort. London: E \& FN Spon.

Gemini Dataloggers. (2017) Temp/RH data loggers monitor thermal comfort levels in domestic dwellings [Online].

Available: https://www.geminidataloggers.com/applications/research/building-monitoringresearch [Accessed 7 November 2017].

Harmeling, Sven., Witting, Maximilian., Bals, Christoph \& Kreft, Sonke (2011) Global climate risk index 2011. Who suffers most from extreme weather events? Weather-related loss events in 2009 and 1990 to 2009. www.germanwatch.org/cri, Germanwatch e.V.

Horton, Radley., Mel, Manishka De., Peters, Danielle., Lesk, Corey., Barlett, Ryan., Helsingen, Hanna., Bader, Daniel., Capizzi, Pasquale., Martin, Shaun \& Rosenzweig, Cynthia In: (2017) Assessing the climate risks in Myanmar. A contribution to planning and decision-making in Myanmar: Technical report. In. New York, USA, Center for Climate Systems Research at Columbia University, WWF-US and WWF-Myanmar

Huang, J.Y., Su, F.X.., Seo, D.H. \& Krarti, M. (2014) Development of 3,012 IWEC2 weather files for international locations (RP-1477). ASHRAE Transactions, 120, (1) 340-355.

IESVE (2015) APACHE: ApacheSim calculation methods IES Virtual Environment, Integrated Environmental Solutions Limited.

IPCC In: Core Writing Team., Pachauri, Rajendra K. \& Meyer, Leo eds. (2015) Climate change 2014: Synthesis report. In. Contribution of Working Groups I, II and III to the Fifth Assessment Report of the Intergovernmental Panel on Climate Change, Geneva, Switzerland.

Jentsch, Mark F.., Bahaj, AbuBakr S. \& James, Patrick A. B. (2008) Climate changes futureproofing of buildings: Generation and assessment of building simulation weather files. Energy and Buildings, 40, (2148) 2148-2168. DOI: 10.1016/j.enbuild.2008.06.005.

Jing, Shenglan., Li, Baizhan., Tan, Meilan \& Liu, Hong (2013) Impact of relative humidityon thermal comfort in a warm environment. Indoor Built Environment, 22, (4) 598-607. DOI: $10.1177 / 1420326 X 12447614$.

Kottek, Markus., Jurgen, Grieser., Beck, Christoph., Rudolf, Bruno \& Rubel, Franz (2006) World map of the Köppen-Geiger climate classification updated. Meteorologische Zeitschrift, 15, (3) 259-263. DOI: 10.1127/0941-2948/2006/0130.

Levins, Richard \& Lewontin, Richard (1985) The dialectical biologist. United States, Harvard University Press.

Loupis, George (1983) The Kaluli longhouse. Oceania Publications, University of Sydney, 53, (4) 358-383. DOI: 10.1002/j.1834-4461.1983.tb01999.x.

Meir, Isaac A. \& Roaf, Susan C. (2006). The future of the vernacular: Towards new methodologies for the understanding and optimization of the performance of vernacular buildings. In: Asquith, Lindsay \& Vellinga, Marcel (eds.) Vernacular architecture in the twenty-first century: Theory, education and practice. London, New York: Taylor \& Francis.

Ministry of Labour In: (2015) The 2014 Myanmar population and housing census: The union report. In. Naypyidaw. 
Nai, Aye. (2010) Myanmar: Heatwave kills 230 in Mandalay (a report from Democratic Voice of Burma) [Online]. Informing humanitarians worldwide. Available: https://reliefweb.int/report/myanmar/myanmar-heatwave-kills-230-mandalay [Accessed 13 November 2019].

NASA (2015) Mean temperature change $\left({ }^{\circ} \mathrm{C}\right)$ projections and mean precipitation change $(\%)$ projections in the 2041-2070 period compared to the 1980-2005 average for Myanmar. The image is created by using the data from NEX gobal daily downscaled climate projections 2015. Available from: https://nex.nasa.gov/nex/projects/1356/

National Weather Service. (2019) The heat Index equation by Lans P. Rothfusz [Online]. Weather Prediction Centre: National Weather Service. Available: https://www.wpc.ncep.noaa.gov/html/heatindex equation.shtml [Accessed 8 August 2019].

Netatmo. (2019) Smart home weather station's technical specifications [Online]. Available: https:/www.netatmo.com/en-gb/weather/weatherstation/specifications [Accessed November 4 2018].

Nguyen, Anh-Tuan., Tran, Quoc-Bao., Tran, Duc-Quang \& Reitera, Sigrid (2011) An investigation on climate responsive design strategies of vernacular housing in Vietnam. Building and Environment, 46, (2011) 2088-2106. DOI: 10.1016/j.buildenv.2011.04.019

Nicol, Fergus., Rudge, Janet \& Kovats, Sari (2005). Safe and warm; effect of climate change on thermal comfort and health. In: Roaf, Sue., Crichton, David \& Nicol, Fergus (eds.) Adapting Buildings and Cities for Climate Change: A 21st Century Survival Guide. An imprint of Elsevier: Architectural Press.

Nicol, J. Fergus \& Humphreys, Michael (2010) Derivation of the adaptive equations for thermal comfort in free-running buildings in European standard EN15251. Building and Environment, 2010, (45) 11-17. DOI: 10.1016/j.buildenv.2008.12.013.

Oakley, David (1961) Tropical houses: A guide to their design. London, B. T. Batsford.

Pal, Jeremy S. \& Eltahir, Elfatih A. B. (2016) Future temperature in southwest Asia projected to exceed a threshold for human adaptability. Nature Climate Change, 6, (2) 197-200. DOI: $10.1038 /$ nclimate2833.

Phyu, Aye Sapay. (2010) More heat records were broken in May: the Department of Meteorology and Hydrology (DMH) [Online]. https://www.mmtimes.com: The Myanmar Times. [Accessed 27 December 2019].

Rapoport, Amos (1969) House form and culture. United State of America, Prentice-Hall.

Roaf, Sue., Crichton, David \& Nicol, Fergus (2005) Adapting buildings and cities for climate change: A 21st century survival guide. An imprint of Elsevier, Architectural Press.

Roaf, Sue \& Nicol, Fergus (2017) Running buildings on natural energy: design thinking for a different future. Architectural Science Review, 60, (3) 145-149. DOI: 10.1080/00038628.2017.1303924.

Robine, Jean-Marie., Cheung, Siu Lan K.., Roy, Sophie Le., Oyen, Herman Van., Griffiths, Clare., Michel, Jean-Pierre \& Herrmann, Francois Richard (2008) Death toll exceeded 70,000 in Europe during the summer of 2003. Comptes Rendus Biologies, 331, (2) 171178. DOI: $10.1016 /$ j.crvi.2007.12.001.

Rosenlund, Hans (2000) Climate design of buildings using passive techniques. Lund University, Housing Development \& Management.

Rothfusz, Lans P. In: (1990) The heat index equation. In. NWS Southern Region Headquarters, Fort Worth, TX.

Sherwood, Steven C. \& Huber, Matthew (2010) An adaptability limit to climate change due to heat stress. Proceedings of the National Academy of Sciences of the United States of America, 107, (21) 9552-9555. DOI: 10.1073/pnas.0913352107. 
Stagno, Bruno (2001). Tropicality. In: Tzonis, Alexander., Lefaivre, Liane \& Stagno, Bruno (eds.) Tropical architecture: Critical regionalism in the age of globalization. Great Britain: Wiley-Academy.

Steadman, R. G. (1979) The assessment of sultriness. Part I: A temperature-humidity index based on human physiology and clothing science. Journal of Applied Meteorology and Climatology, $\quad 18, \quad(1979) \quad 861-873 . \quad$ DOI: $\quad 10.1175 / 1520-$ 0450(1979)018<0861:TAOSPI $>2.0$. CO;2.

Stull, Roland (2011) Wet-bulb temperature from relative humidity and air. Journal of Applied Meteorology and Climatology, 50, (11) 2267-2269. DOI: 10.1175/JAMC-D-110143.1.

Szokolay, Steve. Dilemmas of warm-humid climate house design: heavy vs. lightweight + cooling effect of air movement. Passive and Low Energy Architecture, July, Cambridge, James \& James (Science Publishers), 144-149.

Szokolay, Steven K. (2008) Introduction to architectural science: The basis of sustainable design. Amsterdam ; Boston ; London, Elsevier/Architectural Press.

Tantasavasdi, Chalermwat., Srebric, Jelena \& Chen, Qingyan (2001) Natural ventilation design for houses in Thailand. Energy and Buildings, 33, (2001) 815-824. DOI: 10.1016/S0378-7788(01)00073-1.

Toe, Doris Hooi Chyee \& Kubotab, Tetsu (2015) Comparative assessment of vernacular passive cooling techniques for improving indoor thermal comfort of modern terraced houses in hot-humid climate of Malaysia. Solar Energy, 114, (2015) 229-258. DOI: 10.1016/j.solener.2015.01.035.

Weber, Willi \& Yannas, Simos (2014) Lessons from vernacular architecture. Oxon, Routledge.

WHO (1009). Indoor environment: health aspects of air quality, thermal environment, light and noise. In: Environmental Health in Rural and Urban Development and Housing Unit (ed.) Technical Documents. https://apps.who.int/iris/handle/10665/62723: World Health Organization.

WMO. (2010) European heatwave sets new temperature records [Online]. https://public.wmo.int: World Metrological Organization. Available: https://public.wmo.int/en/media/news/european-heatwave-sets-new-temperaturerecords [Accessed 27 December 2019].

Zune, May (2017) Koppen-Geiger climate shift: 1926-2100 for Myanmar The image is created by using the Google Earth KMZ files provided by Koppen-Geiger web sources: http://koeppen-geiger.vu-wien.ac.at/shifts.htm.

Zune, May., Rodrigues, Lucelia Taranto \& Gillott, Mark. (2018). The sensitivity of roof surface and envelope insulation in naturally ventilated tropical housing: Case study across three climate zones in Myanmar. In: Riffat, Saffa., Su, Yuehong., Liu, Defu \& Zhang, Yingjiang, eds. Sustainable Energy Technologies for Eco Cities and Environment, 17th International Conference on Sustainable Energy Technologies, 21-23 August Wuhan, China, University of Nottingham \& WSSET, 264-273.

Zune, May., Rodrigues, Lucelia Taranto \& Gillott, Mark (2020) Vernacular passive design in Myanmar housing for thermal comfort. Sustainable Cities and Society, 54, -. DOI: 10.1016/j.scs.2019.101992. 